\title{
In situ study of model organic friction modifiers using liquid cell AFM; saturated and mono-unsaturated carboxylic acids
}

\author{
Campen, S. ${ }^{a}$, Green, J. H. ${ }^{\text {, }}$ Lamb, G. D. ${ }^{\text {b }}$, Spikes, H.A. ${ }^{a}$ \\ a Tribology Group, Department of Mechanical Engineering, Imperial College London, SW7 2AZ, UK \\ b Castrol Ltd., Pangbourne, Reading, RG8 7QR, UK
}

\section{ABSTRACT}

Fatty acids and their derivatives have been used as model organic friction modifiers for almost a century, but there is still debate as to the nature of the boundary films that they form on rubbed surfaces. In this study, in situ liquid cell atomic force microscopy (AFM) is used to monitor the self-assembly of boundary films from solutions of fatty acids in alkanes on to mica surfaces. Because the mica surfaces are wholly immersed in solution it is possible to study directly changes in the morphology and friction of these films over time and during heating and cooling.

It has been found that stearic and elaidic acid, that are able to adopt a linear molecular configurations, form irregular islands on mica that are tens to hundreds of microns in diameter and typically $1.6 \mathrm{~nm}$ thick, corresponding to domains of tilted single monolayers. At a relatively high concentration of $0.01 \mathrm{M}$, stearic acid in hexadecane forms an almost complete monolayer, but at lower concentrations, in dodecane solution and for elaidic acid solutions these films remain incomplete after prolonged immersion of more than a day. The films formed by fatty acids on mica are displaced by repeated scanning in contact mode AFM but can be imaged without damage using tapping mode AFM.

Rubbed quartz surfaces from a sliding ball-on-disc test were also scanned ex-situ using AFM and these showed that stearic acid forms similar monolayer island films on quartz in macroscale friction experiments as are found on mica.

Oleic acid solutions behave quite differently from stearic acid and elaidic acid, forming irregular globular films on both mica and rubbed quartz surfaces. This is believed to be because its cis-double bond geometry means that, unlike its trans-isomer elaidic acid or saturated stearic acid, it is unable to adopt a linear molecular configuration and so is less able to form close-packed monolayers.

\section{KEYWORDS}

Organic friction modifier; boundary friction; AFM, in situ; stearic acid 


\section{INTRODUCTION}

A companion paper [1], describes the application of in situ liquid cell atomic force microscopy (AFM) to investigate the self-assembly and morphology of boundary films formed by octadecylamine on mica surfaces. The current paper employs the same experimental approach to study boundary film formation by various long chain carboxylic acids.

\subsection{Carboxylic acids as organic friction modifiers}

Almost exactly one hundred years ago, it was discovered that the addition of a small concentration of oleic acid to mineral oil was able to reduce friction and thus increase the efficiency and reliability of machine components [2]. This acid very soon became widely employed as the first lubricant additive and its importance can be gauged from the fact that open release of the patent describing its use was withheld by the UK Admiralty for 18 months until after the 1914-1918 war [2]. Various mechanisms for this behaviour were proposed but it soon became accepted that the additive worked by adsorbing on polar metal surfaces to form a low shear strength separating film, as graphically described by Allen in 1919 [3];

In the extreme case we may picture each of the metallic surfaces covered with a layer of oil one molecule thick, resembling a piece of velvet firmly glued to the metal with the pile outwards. Two such velvet-clad surfaces can glide over one another with but little friction.

In the early 1920s, the term "boundary lubrication" was coined to describe reduction of friction by the adsorption of long chain, polar molecules on rubbing surfaces [4]. This class of additive, based on amphiphilic molecules with a long hydrocarbon chain having a polar functional group at one end, are now widely employed in the formulation of energy-efficient lubricants and are called organic friction modifiers (OFMs). Nowadays, free long chain carboxylic acids (often termed fatty acids) are rarely used as OFMs in engine or transmission formulations due to bearing metal corrosion issues [5,6], although they are still employed in some metal-working applications. However, esters that are designed to release fatty acids in small quantities of free acid during use and polyfunctional species in which the corrosive response of the carboxylic group is reduced by neighbouring groups are widely employed.

There has been very extensive academic research into the friction-reducing behaviour of carboxylic acids as friction modifiers. It was found that solutions of linear, saturated carboxylic acids in hydrocarbons, when used at concentrations of greater than about $0.0001 \mathrm{M}(\sim 0.05 \% \mathrm{wt}$.) give greatly reduced friction with a wide range of metal-metal tribopairs [7]. Friction reduction occurs when the number of carbon atoms in the chain exceeds about 4 , and increases with increasing carbon chain length. There is, however, still some disagreement about whether or not friction levels out above a critical chain length [8-10]. Branched chain acids were generally found less ineffective than straight chain ones [11]. It was shown that to reduce friction, enough carboxylic acid must be present to form a 
complete vertically oriented monolayer [8]. Research also showed that single monolayers of long chain carboxylic acid deposited on surfaces using the Langmuir-Blodgett technique were able to reduce friction just as well as when the surfaces were immersed in the acid solution [12,13]. Based on all these observations, the classical model of OFM behaviour was developed - that these additives adsorb on polar surfaces to form close-packed, vertically-oriented monolayers. The weak interaction potentials and very limited interpenetration between methyl end groups of monolayers on opposing, sliding surfaces results in a very low shear strength interface and thus low friction [14]. An important feature of these vertically-oriented monolayers is that Van-der-Waals forces between adjacent long, straight alkyl chains confer considerable strength to the monolayer, such that monolayers of long chain molecules are able to withstand the very large applied pressures present at asperity-asperity contacts $[15,16]$.

Although this monolayer model of OFM behaviour generally prevails, it should be noted that there is also a considerable body of literature to indicate that in some cases long chain carboxylic acids can form films considerably thicker than a single monolayer [17].

There has been considerable debate as to the nature of the bond between carboxylic acid OFMs and metal surfaces, in particular whether the molecules are physically adsorbed as the free acid or chemically react with the surfaces to form metal carboxylates. This question was discussed by Bowden and Tabor, who concluded that carboxylic acids generally react with the oxides on metal surfaces to form metal carboxylates [7].

Most research on carboxylic acid-based friction modifiers has studied metals, showing that fatty acids are effective in reducing friction of reactive metals, including iron, but not of unreactive metals such as chromium and silver [9]. The latter is quite surprising since fatty acids have been shown to adsorb from hexadecane to form near-complete monolayers on such metals [18]. Some work has also been carried out using other substrates and Hardy found much less reduction of friction by fatty acid solutions with glass compared with steel [4] while Studt noted very little friction reduction with silicon carbide [11].

The majority of academic research on carboxylic acid friction modifiers has studied saturated carboxylic acids, although there has been some research on oleic acid, which has one double $\mathrm{C}=\mathrm{C}$ bond, and fatty acids with multiple double bonds such as linoleic acid and linolenic acid. Derivatives of such acids are often used as commercial OFMs.

Jahanmir and Beltzer compared the friction-reducing properties of copper lubricated by solutions of stearic acid, oleic acid and elaidic acid in refined mineral oil [14]. Elaidic acid is the trans isomer of oleic acid. They found that as concentration of acid was increased for each carboxylic acid, friction decreased, to reach a limiting value at high concentration. However, stearic acid produced a low friction film at much lower concentration than did oleic acid, while elaidic acid was intermediate between the two. The asymptotic friction coefficient reached at high concentration by stearic acid was also lower than that reached for the two unsaturated acids. 
Fox et al. compared the friction behaviour on steel of various concentrations of stearic and oleic acid dissolved in sunflower oil and found that stearic acid gave much lower friction (and wear) than oleic acid at low concentration but similar friction at high concentration [19].

Lundgren et al. compared the film-forming behaviour of stearic, oleic, linoleic and linolenic acid solutions in hexadecane using a surface forces apparatus [20]. They found that stearic and oleic acids formed monolayers on the opposing mica surfaces, with thickness indicative of vertical molecular orientation. Linoleic and linolenic acid formed thicker films, which the authors interpreted as resulting from the presence of horizontally-oriented layers between the monolayers on the two mica surfaces. By contrast, using quartz crystal microbalance to study adsorption on steel surfaces, Lundgren and co-workers found only partial monolayers formed by stearic acid and oleic acid in hexadecane [21].

In a recent study by the authors, the friction properties of stearic acid, oleic acid and elaidic acid solution in a steel-steel sliding contact were compared [22]. It was found that both stearic acid and elaidic acid solutions gave extremely low friction coefficient (typically 0.05) at very low sliding speed, which increased linearly with log(speed) to reach a value of ca $0.08-0.09$ at a sliding speed of $1 \mathrm{~mm} / \mathrm{s}$. By contrast, oleic acid solution gave friction coefficient of ca 0.1 that was constant over the whole speed range. The authors suggested that low friction that increases logarithmically with speed is characteristic of close-packed vertically-oriented monolayers and that the trans arrangement of elaidic acid enables its molecules, like those of stearic acid, to adopt a linear configuration and thus form such monolayers. Oleic acid, however, due to its cis arrangement, cannot adopt a linear configuration and thus cannot form close-packed monolayers at the concentrations tested.

\subsection{AFM studies of carboxylic acid self-assembly}

Surprisingly little previous research has used AFM to study self-assembled films formed by fatty acids and in all of it AFM has been applied ex-situ, where a surface is immersed in solution to form a film and then withdrawn from solution and dried prior to study. The potential disadvantages of this ex-situ approach have been discussed in a companion paper [1].

Benitez and co-workers studied the self-assembled films formed on mica by hexadecanoic acid solution in chloroform [23,24]. Mica was immersed in various concentration solutions for $30 \mathrm{~s}$, withdrawn, dried in a stream of $\mathrm{N}_{2}$ gas and stored, before being tested using contact mode AFM. It was found that the acid initially formed dendritic islands of height $1.5 \mathrm{~nm}$ to 2 $\mathrm{nm}$ and width approx. $0.75 \mu \mathrm{m}$, covering about $15 \%$ of the mica surface. For higher acid concentrations the coverage increased to a maximum of $30 \%$ during prolonged storage. The authors suggested that the islands were tilted monolayers of acid molecules, weakly bound to the mica surface, although they conjectured that at high solution concentrations, acid dimers might adsorb [24]. 
Zhang et al. used a similar approach to study the impact of relative humidity on the selfassembled films formed on mica by arachidic acid (C20) solution in chloroform [25]. The films formed initially consisted of almost complete, tilted monolayers with small pinholes. During AFM scanning in moderate humidity conditions, the number of pinholes increased and then the pinholes were enlarged by removal of material at the edges. Upon resting, some recovery took place. At higher humidity the damage caused to the monolayers by AFM scanning was reduced. The authors suggested that the presence of adsorbed water molecules in and adjacent to the pinholes might increase mobility of the arachidic acid film and thus promote rapid healing.

Song et al. used ex-situ AFM to study the films formed on mica from hexadecanoic acid solution in ethanol [26]. When the mica was exposed to solution for very short times, partial coverage was seen but this increased to full coverage for exposure times of more than 60 minutes. In contrast to the studies by Benitez [23] and Zhang [25], who found monolayers, the thickness of the films in the study indicated bilayers and multiple bilayers. This is to be expected for the self-assembly of amphiphiles from polar solvents on to polar surfaces, since the film formed needs to be polar at both the film-solid interface and at the film-liquid one.

Taylor and Schwartz [27] and Lim et al. [28] have both used ex-situ AFM to study the films formed by fatty acid solution on alumina. Taylor and Schwartz studied film formation by octadecanoic acid from hexadecane. They found that islands of monolayer thickness were formed initially but that coverage increased with immersion time to reach a complete monolayer after about 1 minute with freshly annealed (i.e. dry) sapphire, but took 24 hours to reach a monolayer on sapphire exposed to ambient air. Lim et al. immersed sapphire in octadecanoic acid solution in hexadecane to prepare monolayers and then immersed these in water for varying periods before mapping the sapphire surfaces using AFM. They found that the film was progressively removed by molecular desorption into water.

There appears to have been no published work to date to study the topography and friction properties of self-assembled films of fatty acid OFMs on solid surfaces using in-situ AFM, where the surface is fully immersed in solution and scanned using an AFM tip in a liquid cell. The current paper describes such a study. 


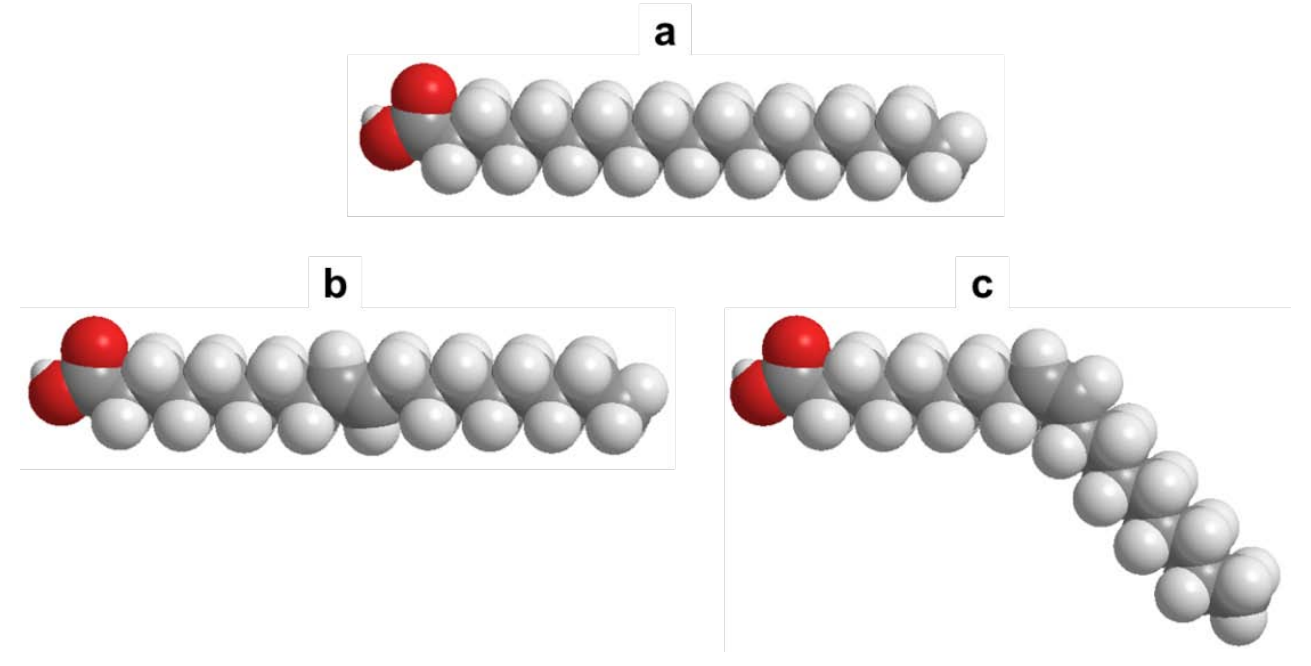

Fig. 1 Molecular structures of stearic acid (a), elaidic acid (b) and oleic acid (c)

\subsection{The chemistry of the mica surface}

Muscovite mica has the chemical formula $\mathrm{KAl}_{2}\left(\mathrm{Si}_{3} \mathrm{Al}\right) \mathrm{O}_{10}(\mathrm{OH})_{2}$ and it cleaves between aluminosilicate layers [26]. Negatively charged aluminosilicate layers are bound to an intermediate "sandwiched" layer of positively charged potassium ions and upon cleavage these potassium ions become approximately equally distributed between the two new surfaces [29].

In this study, it is important to consider the role played by potassium cations located at the mica surface since they may react with carboxylic acid to form insoluble potassium carboxylate salt. The presence of metal cations at the substrate surface is of particular interest since the likelihood of reaction between iron oxide and carboxylic acid friction modifier resulting in the formation of a chemisorbed iron carboxylate film has been a topic of much debate amongst scientists in the field. Whilst it has been argued that the reaction to yield iron carboxylate is thermodynamically unfavourable [30], more recent surface analyses by techniques such as ToF-SIMS and FTIR support the formation of metal carboxylate [3133].

To investigate the role played by potassium cations in the self-assembly of carboxylic acids, potassium-free mica surfaces are prepared by ion exchange in aqueous solutions. There is conflicting information as to the optimum experimental conditions required to displace $\mathrm{K}^{+}$ ions by $\mathrm{H}^{+}$. Pashley found that at $\mathrm{pH} 7$ few $\mathrm{K}^{+}$ions were exchanged by $\mathrm{H}^{+}$, but that by decreasing the $\mathrm{pH}$ to 6 , all the potassium ions could be replaced [34]. $\mathrm{Xu}$ and Salmeron were able to use deionized water for the preparation of mica surfaces with $\mathrm{H}^{+}$ions [35]. However, Osman et al. showed that dissolution of atmospheric $\mathrm{CO}_{2}$ in water leads to the formation of carbonic acid that can participate in hydroxonium ion formation by lowering the $\mathrm{pH}$, thus facilitating ion exchange [36]. Gaines and Rutkowski reported that $\mathrm{Al}^{3+}$ and $\mathrm{Si}^{4+}$ could be extracted from mica at high acidity [37], while Pashley observed no damage to the 
mica surface at $\mathrm{pH} 3$ [34]. $\mathrm{Xu}$ and Salmeron also showed that ion-exchange by $\mathrm{H}^{+}$is reversible [35]. This suggests that the adsorbed cation must in fact be $\mathrm{H}_{3} \mathrm{O}^{+}$, not $\mathrm{H}^{+}$, since it possesses a charge density comparable to $\mathrm{K}^{+}$.

\section{EXPERIMENTAL}

\subsection{Materials and reagents}

The fatty acids, stearic acid ( $\left.₹ 98.5 \%, 284.48 \mathrm{gmol}^{-1}\right)$, oleic acid $\left.₹ 99 \%, 282.46 \mathrm{gmol}^{-1}\right)$ and elaidic acid $¥ 99.0 \%, 282.46 \mathrm{gmol}^{-1}$ ), were used as supplied. Hexadecane (99\%) and dodecane (99\%), used as base oil, were cleaned with silica (Fluka, chromatography, 60) and alumina (Sigma-Aldrich, Brockmann Activity I, basic) molecular sieves and stored over alumina to be filtered immediately before use. Solutions of the additives in base oil were prepared at concentrations of $0.01,0.001$ and $0.0001 \mathrm{M}$ as required. All reagents were purchased from Sigma-Aldrich.

Muscovite mica discs of $14 \mathrm{~mm}$ diameter were acquired from Agar Scientific (Stansted, UK). These had RMS roughness of ca. $0.1 \mathrm{~nm}$. Fused quartz balls of $6 \mathrm{~mm}$ diameter and fused quartz discs of $14 \mathrm{~mm}$ diameter and $3 \mathrm{~mm}$ thickness were obtained from the Technical Glass Company (Cambridge, UK). Quartz balls and discs had RMS roughness of $1.5 \mathrm{~nm}$ and 0.3 $\mathrm{nm}$ respectively. The fused quartz specimens had hardness of 1050 VPN. Steel AISI 52100 balls of $6 \mathrm{~mm}$ diameter were acquired from PCS Instruments (Acton, UK). These had RMS roughness of $6 \mathrm{~nm}$ and were of bearing grade steel through-hardened to 760 VPN.

\subsection{Preparation of mica substrates}

Mica was attached to steel discs using Araldite 2-part epoxy resin ready for mounting on the magnetic stage in the AFM head. Immediately before use the mica was freshly cleaved in either air or dodecane. Cleavage in air was made using adhesive tape. Adhesive tape was gently pressed against the exposed flat surface of the mica substrate, parallel to the cleavage plane. The tape was then slowly peeled away from the surface. The tape was investigated under light to reveal the removed layer of mica and verify that cleavage had been successful. This process was repeated three times. Cleavage in dodecane was carried out using a stainless steel blade. A crystallising dish was filled with clean dodecane. The mica sample and stainless steel blade were immersed in the dodecane. The stainless steel blade was then firmly pressed against the curved edge of the mica disc, approximately perpendicular to the cleavage plane. Once the blade was inserted at the edge of the mica it was slowly pushed across and away from the sample to lift away the top layer of mica.

Potassium-free mica surfaces were prepared by placing both top and bottom-cleaved mica specimens in hydrochloric acid for 20 hours. Hydrochloric acid (Fluka, $0.01 \mathrm{M}$ standard solution) was diluted with deionised water to give a $\mathrm{pH}$ of 5 . Chemically inert plastic tweezers were used instead of stainless steel tweezers to handle the mica to prevent corrosion of steel and release of metal cations into the acid solution. After immersion in acid, the mica specimens were removed and rinsed 5 times with deionised water. Excess 
water was poured off the surface and the remaining water was removed with a heated blowdryer so that no water droplets could be seen under the optical microscope at 500X magnification. Modified mica substrates were adhered to steel pucks with adhesive pads (Veeco Probes) rather than Araldite 2-part epoxy resin to prevent contamination of the prepared mica surface with amines, which are released during the curing of the latter.

\subsection{Preparation of quartz ball-on-disc friction surfaces}

Immediately before use, the steel balls were cleaned by ultrasonication in a bath of toluene for $30 \mathrm{~min}$. The steel specimens were then rinsed, first with clean toluene and then with acetone. Quartz balls and discs were rinsed with toluene and acetone. Specimens were dried using a heated blow dryer.

Ball-on-disc pure sliding friction tests were carried out using a UMT-2 tribometer equipped with an ultra-low speed rotary drive and high range dual force sensor from CETR (Centre for Tribology Inc., Campbell, California, USA). During friction tests, the ball was loaded against the rotating, flat surface of the disc. Both ball and disc were immersed in carboxylic acid solution in hexadecane. Friction tests were carried out using a load of $4 \mathrm{~N}$, a sliding speed of $1 \times 10^{-3} \mathrm{~ms}^{-1}$ and a temperature of $35^{\circ} \mathrm{C}$.

After a friction test the lower disc specimen was left immersed in test lubricant until ready for AFM imaging; this was typically carried out within 1-2 $\mathrm{h}$. Once removed from the lubricant solution, the disc was held level so that a liquid film remained on the upper friction surface. Excess lubricant was removed from the lower surface by firmly pressing the underside of the specimen against a dry paper towel, a toluene-soaked paper towel, an acetone-soaked paper towel and finally a dry paper towel. The underside of the quartz specimen was then attached to a steel disc using an adhesive pad, ready for mounting on the magnetic plinth in the AFM. A temperature of $35^{\circ} \mathrm{C}$ was maintained inside the AFM, however, in the intervening time the specimens cooled to a room temperature of $22^{\circ} \mathrm{C}$.

\section{$2.4 \quad$ AFM instrumentation and measurements}

All AFM measurements were made using a Veeco Multimode SPM with Nanoscope IV controller and either a vertical "J" or "E" scanner. Contact and tapping mode AFM in liquid was achieved using a liquid cell. In contact mode, height and lateral force images were obtained, while in tapping mode, height and phase images were generated. Liquids were introduced to the liquid cell via pipette. Triangular $\mathrm{Si}_{3} \mathrm{~N}_{4}$ cantilevers with a backside gold coating (model NP-S) were obtained from Veeco Probes Ltd. A long wide-legged cantilever was employed for all measurements. According to the supplier's specifications, this cantilever nominally has length of $196 \mu \mathrm{m}$, leg width of $41 \mu \mathrm{m}$, free resonant frequency of 20 $\mathrm{kHz}$ and spring constant of $0.12 \mathrm{~N} / \mathrm{m}$.

For force spectroscopy, normal deflections of the AFM cantilevers were calibrated using the reference cantilever method [37].

To determine the effect of temperature on film formation by carboxylic acids a vertical "J" scanner with sample heater attachment (Veeco Instruments, Santa Barbara, California, USA) was used. The heating element was located directly underneath the magnetic 
specimen plate, fitted inside the scanner. The temperature set-point was adjusted in the heater controller. The tip was disengaged during heating and cooling and once the set temperature had been reached, the sample was left for $5 \mathrm{~min}$ before re-engaging the tip and scanning.

\section{$3 \quad$ RESULTS}

\subsection{Mica in alkane and after introduction of stearic acid solution}

In an initial experiment an air-cleaved mica surface was imaged first in hexadecane and then after the injection of $0.001 \mathrm{M}$ stearic acid solution. Fig. 2 shows two pairs of $1 \mu \mathrm{m} \times 1 \mu \mathrm{m}$ contact mode AFM height and lateral force images of an air-cleaved mica surface. The first pair 2(a) and 2(b) are for mica immersed in hexadecane. The surface is featureless except for small, ca. $10 \mathrm{~nm}$, diameter spots. The origin of these is not known but they may correspond to small contamination particles adhering to the mica when it was cleaved. They were not observed in any subsequent experiment.
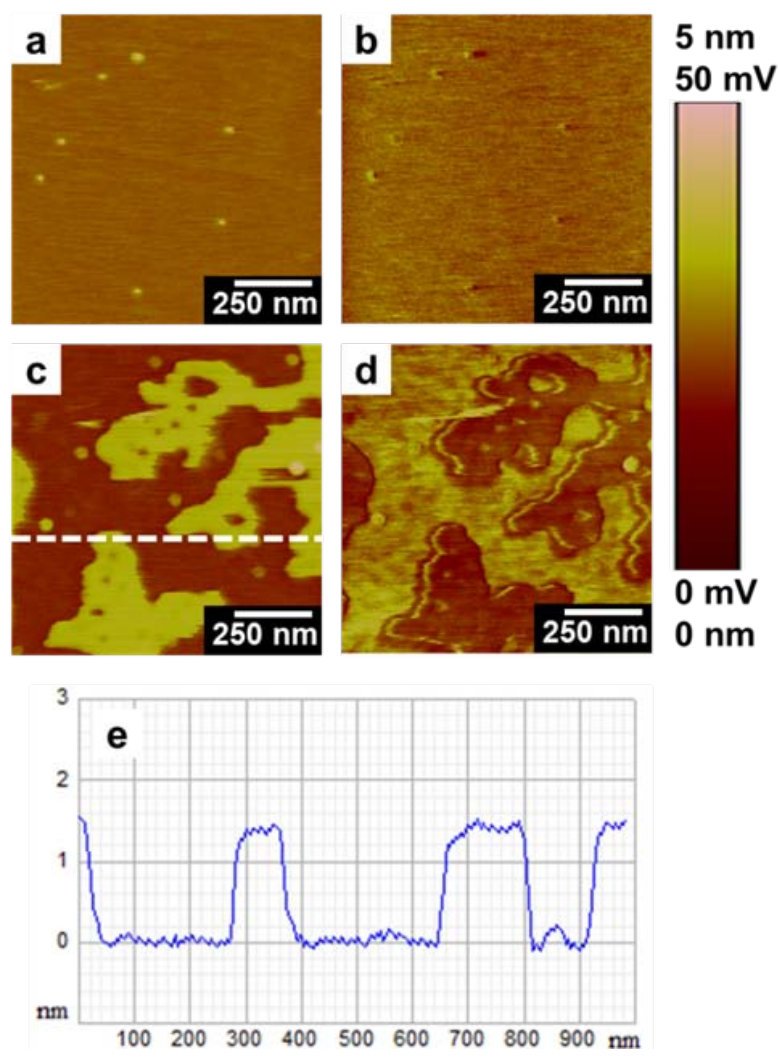

Fig. 2 Contact mode AFM height $(a, c)$ and simultaneously-obtained lateral force $(b, d)$ images of mica in hexadecane $(a, b)$ and after introduction of $0.001 \mathrm{M}$ stearic acid solution in hexadecane $(c, d)$; lateral force is higher (bright contrast) on the uncovered mica surface

Figs. 2(b) and 2(d) show the surface shortly (within 6 minutes) after injection of a $0.001 \mathrm{M}$ stearic acid solution in hexadecane into the liquid cell. The relative volumes of the cell and 
the injected solution mean that the final stearic acid concentration is ca. $0.0004 \mathrm{M}$. Very irregular islands are formed of diameter ca $250 \mathrm{~nm}$ and, from the profile shown in Fig. 2(e), of height $1.4 \mathrm{~nm}$. These are believed to correspond to islands of tilted, vertically-oriented monolayers of the acid, as reported for many surfactants in AFM studies [23,25,39-42]. The height suggests a tilt angle of approx. $56^{\circ}$ from the surface normal. The monolayer islands show lower lateral force than the regions between the islands. Fig. 2(b) also shows small, isolated round spots similar to those seen in the hexadecane scan, suggesting that these persisted after injection of stearic acid solution.

Fig. 3 shows a series of contact mode scans on one region of the mica surface after injection of stearic acid, taken from the same experiment as shown in Fig. 2. Figs. 3(a) and 3(b) show height during two successive $1 \mu \mathrm{m}$ scans and indicate that the islands are progressively removed by scanning. Fig. 3(c) is a $3 \mu \mathrm{m}$ scan taken immediately after this and shows an almost bare region in the centre, corresponding to the previously scanned 1 $\mu \mathrm{m}$ area. Figs. 3(d) and 3(e) show two further $3 \mu \mathrm{m}$ scans in which the surface is being progressively depleted of islands. Finally, the scanned size was expanded to $10 \mu \mathrm{m}$ as shown in Fig. 3(f). The central, almost bare, $3 \mu \mathrm{m}$ scan area can be seen very clearly. Figs. $3(\mathrm{~g})$ and $3(\mathrm{~h})$ show the final topography and lateral force images while Fig. 3(i) shows the height profile along the dashed line in $3(\mathrm{~g})$.
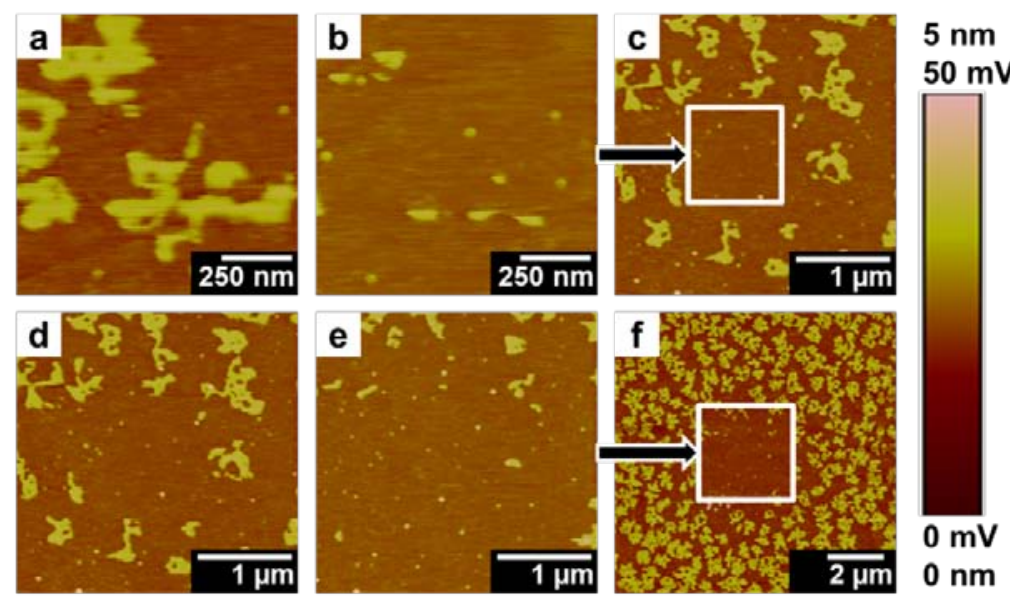

$0 \mathrm{~nm}$
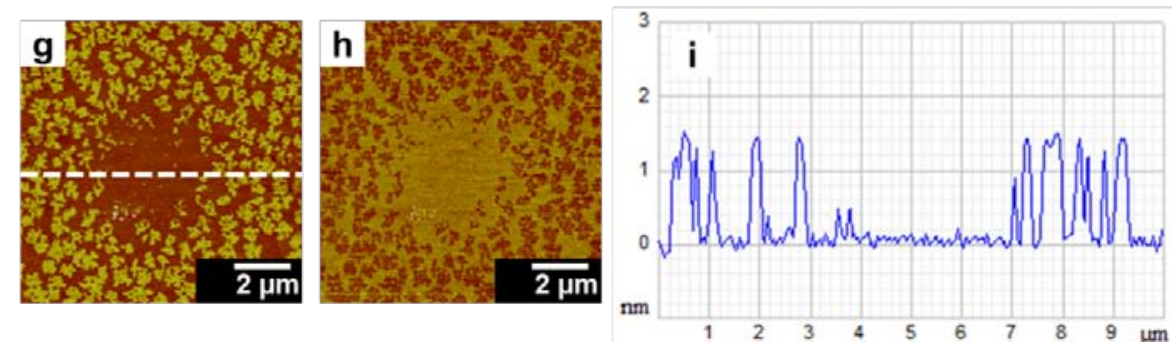

Fig. 3 Contact mode AFM height images showing removal of stearic acid film by loaded scanning at scan sizes of $1 \mu \mathrm{m}(\mathrm{a}, \mathrm{b}, \mathrm{c})$ and $3 \mu \mathrm{m}(\mathrm{d}, \mathrm{e}, \mathrm{f})$; height $(\mathrm{g})$ and lateral force $(\mathrm{h})$ images showing void in film; line profile of $g(i)$ 
These results show that the stearic acid monolayer islands are quite weakly bonded to the surface since they are displaced by the scanning tip. Also, the acid molecules are not displaced laterally to the edges of the scanned region but are dislodged into the liquid phase. It should be noted that when AFM imaging was carried out in tapping mode, the islands were not removed, even after multiple scans.

\subsection{Adsorption of carboxylic acids from solutions of known concentration}

In these experiments, cleaved mica surfaces were imaged in stearic acid solution in hexadecane and in stearic acid, elaidic acid and oleic acid solutions in dodecane. Concentrations of 0.01 and $0.001 \mathrm{M}$ were used and since the liquid cell was filled with carboxylic acid solution from the outset, the concentrations present are known precisely.

Fig. 4 gives an overview of the experimental results and permits a comparison of the films formed by the different carboxylic acids in both hexadecane and dodecane solvents. For all carboxylic acids a higher surface coverage is achieved in more concentrated solution. The surface coverage achieved by the carboxylic acids follows the trend: stearic acid > elaidic acid > oleic acid. For stearic acid higher surface coverages are produced in hexadecane than in dodecane solvent.

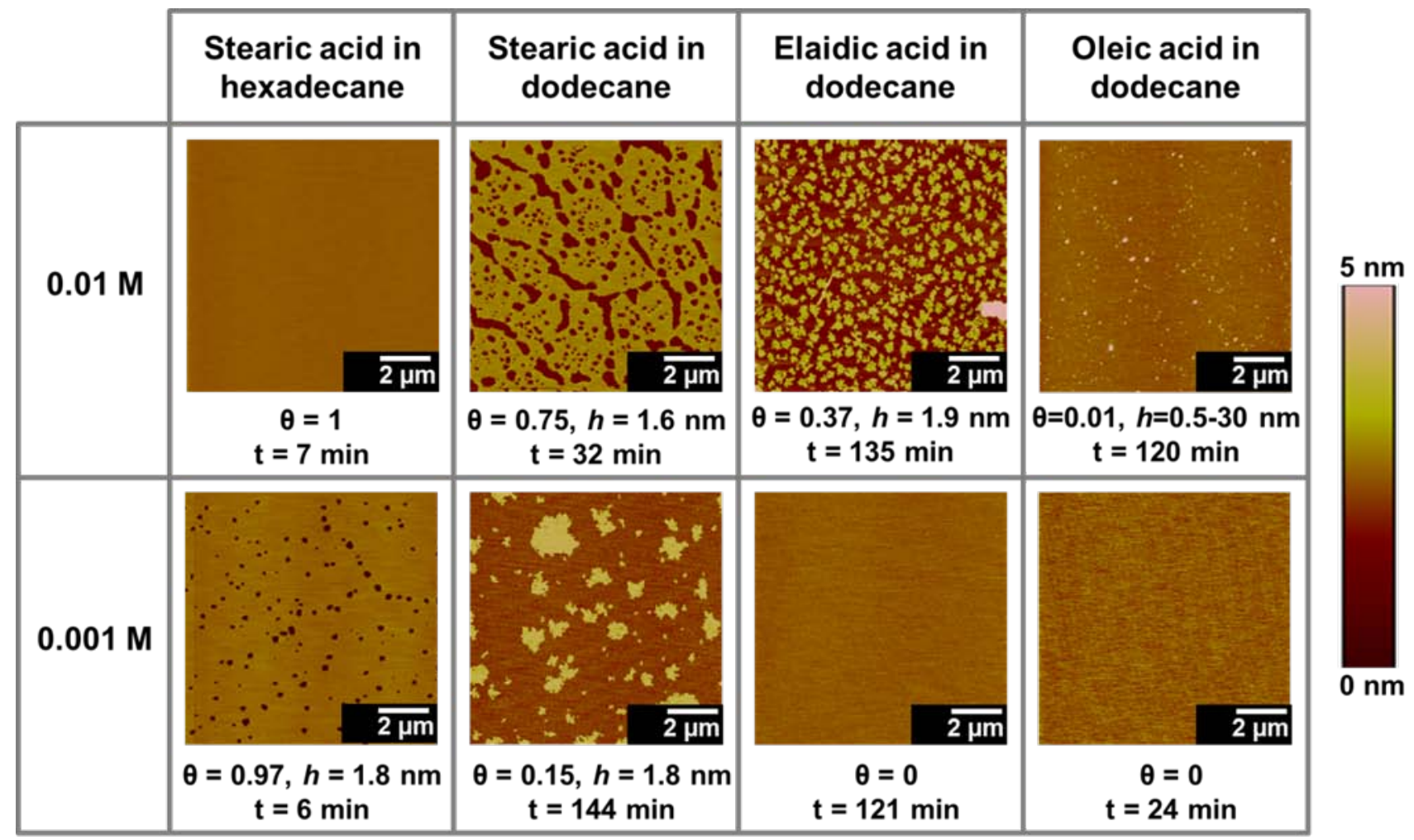

Fig. 4 Summary of results comparing films formed on mica by saturated and monounsaturated carboxylic acids in hexadecane and dodecane solvents at concentrations of 0.01 and $0.001 \mathrm{M}$; AFM height images; $\theta$ is surface coverage, $h$ is film thickness and $\mathrm{t}$ is time in solution 
In $0.01 \mathrm{M}$ stearic acid solution in hexadecane a complete monolayer is formed on mica within 3 min., i.e. the time taken to commence scanning. The appearance of the film did not alter throughout the course of the AFM experiment, which lasted $56 \mathrm{~min}$. Fig. 5 shows the contact mode AFM height and lateral force images obtained. Note the decreased height scale bar of $500 \mathrm{pm}$. Although the film is apparently complete, there is quite a marked variation in lateral force across the surface, as shown in Fig. 5(b). At first sight the height image, Fig. 5(a) appears featureless. However close inspection reveals regions where the height is slightly augmented, by less than $0.1 \mathrm{~nm}$, and these regions correspond to the regions of lower friction. The monolayer film, although complete, thus appears to have structure, possibly with regions of different molecular tilt direction or slight variations in packing density.
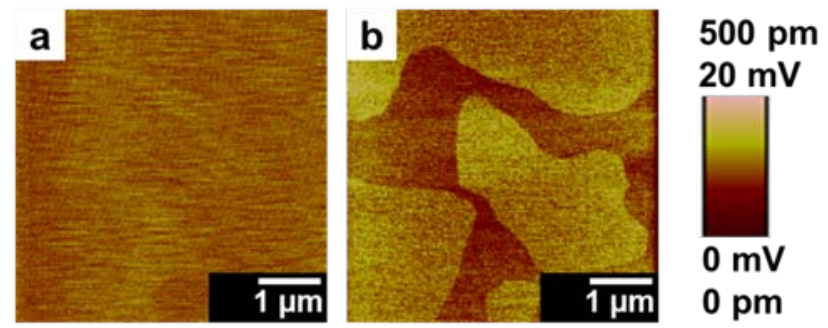

Fig. 5 Contact mode AFM height (a) and lateral force (b) images showing complete stearic acid monolayer on mica in $0.01 \mathrm{M}$ solution in hexadecane

With $0.001 \mathrm{M}$ stearic acid solution in hexadecane, a monolayer with pinhole inclusions is formed a shown in Fig. 6.
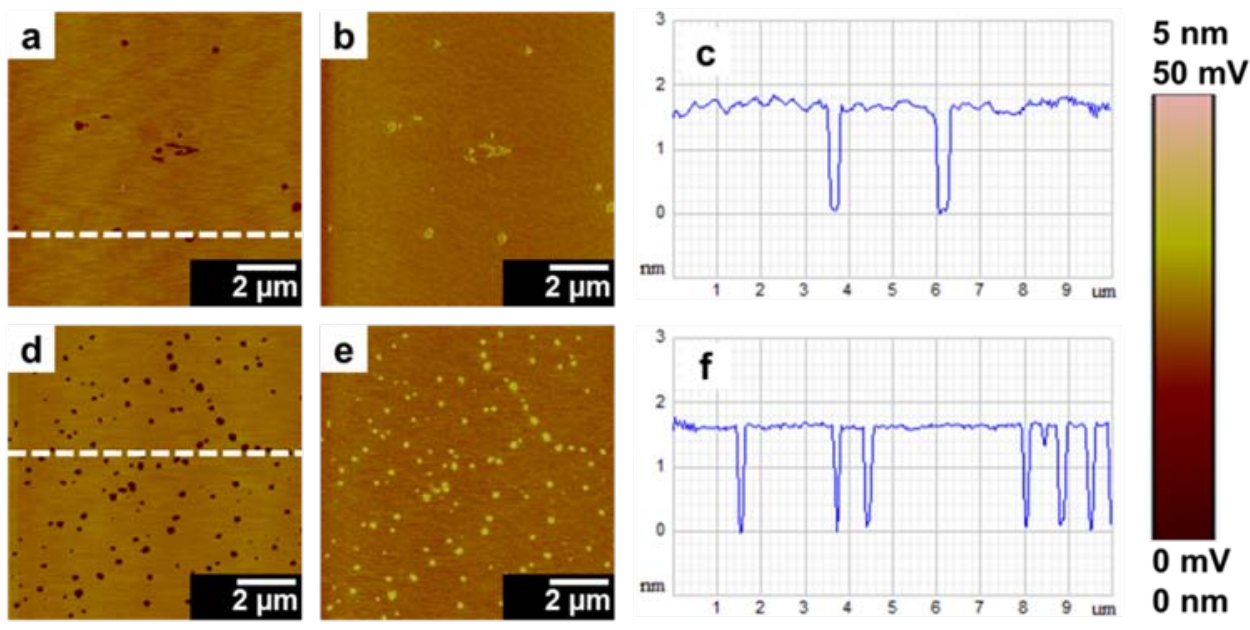

Fig. 6 Contact mode AFM height ( $a, d)$ and lateral force $(b, e)$ images of stearic acid monolayer with pinhole inclusions on mica in $0.001 \mathrm{M}$ solution in hexadecane during two separate experiments; line profiles of $a(c)$ and $d(f)$

These pinholes have diameters of $100-400 \mathrm{~nm}$ and a depth $1.6 \mathrm{~nm}$. The pinholes display higher friction than the $\mathrm{CH}_{3}$ terminated stearic acid monolayer film. In the first experiment $(6 a-c)$ the surface coverage is calculated to be 0.99 , while in the repeat experiment (6d-e) a 
greater number of pinholes are observed and consequently a slightly lower surface coverage of 0.97 is achieved. Assuming an all-trans configuration of the adsorbed stearic acid molecules and no film within the pinholes, it is calculated that the molecules are tilted $50^{\circ}$ from the surface normal.

The adsorption of stearic acid onto mica from solution in the shorter, 12-carbon dodecane was investigated. In $0.01 \mathrm{M}$ solution a low friction partial monolayer containing circular holes is observed. Using depth profile analysis the film height is calculated to be 1.6 and $1.5 \mathrm{~nm}$ and the surface coverage 0.75 and 0.85 in contact and tapping modes respectively. The film formed within 3 min., i.e. before scanning commenced, and did not alter in appearance throughout the 3.5 hour duration of the experiment. In contact mode some of the holes appeared elongated which gave the film a patchwork appearance, as illustrated in Fig. 4. These elongated holes were not visible when the same area was scanned in tapping mode. It is postulated that these elongated holes demarcate former inter-island spaces and indicate that the last stage of film growth was an island (mica continuous phase) to monolayer (stearic acid continuous phase) transition. It is likely that in contact mode the applied forces are high enough for the tip to penetrate the film at weak points. If the last stage of film growth occurs at the boundaries of former islands, it is possible that the film in these locations has less stability and is thus more easily disrupted by the tip. The mechanism of the transition from isolated islands to continuous film may be predominantly via translational motion of pre-adsorbed stearic acid molecules across the mica surface rather than adsorption of new molecules from the bulk solution. This would lead to these molecules exhibiting larger intermolecular separations in order to bridge the gaps between islands and in turn would reduce the strength of the lateral van der Waals interactions that help stabilise the film. A repeat experiment yielded a similar result, i.e. a continuous film with approximately circular holes. In this instance, the film height was $1.5 \mathrm{~nm}$ and the surface coverage 0.90 .

An experiment was also carried out using dodecane-cleaved mica rather than air-cleaved mica. Again, a low friction monolayer film containing holes is observed. In this case, the holes were irregularly shaped. Using line profile and depth analysis it is calculated that the film height is $1.5 \mathrm{~nm}$ and the surface coverage 0.92 , similar to the values observed with aircleaved mica. This suggests that the cleavage medium does not have a significant effect on stearic acid adsorption. It is noted that the surface coverage achieved in $0.01 \mathrm{M}$ stearic acid solution in dodecane is lower than that which is achieved at one tenth of this concentration in hexadecane.

In $0.001 \mathrm{M}$ stearic acid solution in dodecane, a film grows on mica gradually over time, Fig. 7. The initial stages of film formation and subsequent film growth were monitored in contact mode AFM, as shown in Figs. 7(a-d). It is found that stearic acid initially adsorbs forming islands of approximately $2.3 \mathrm{~nm}$ height and $1 \mu \mathrm{m}$ diameter. In the next stage of film growth, smaller islands form in between these initial islands. These smaller islands have an approximate height of $1.4 \mathrm{~nm}$ and diameters of 0.3 to $0.5 \mu \mathrm{m}$. In the subsequent stage of film growth, both the large and small islands grow. After $33 \mathrm{~min}$ in solution, the large islands 
display lower friction than the small islands; and both show lower friction than the mica substrate, as can be sees in Fig. 7(h).
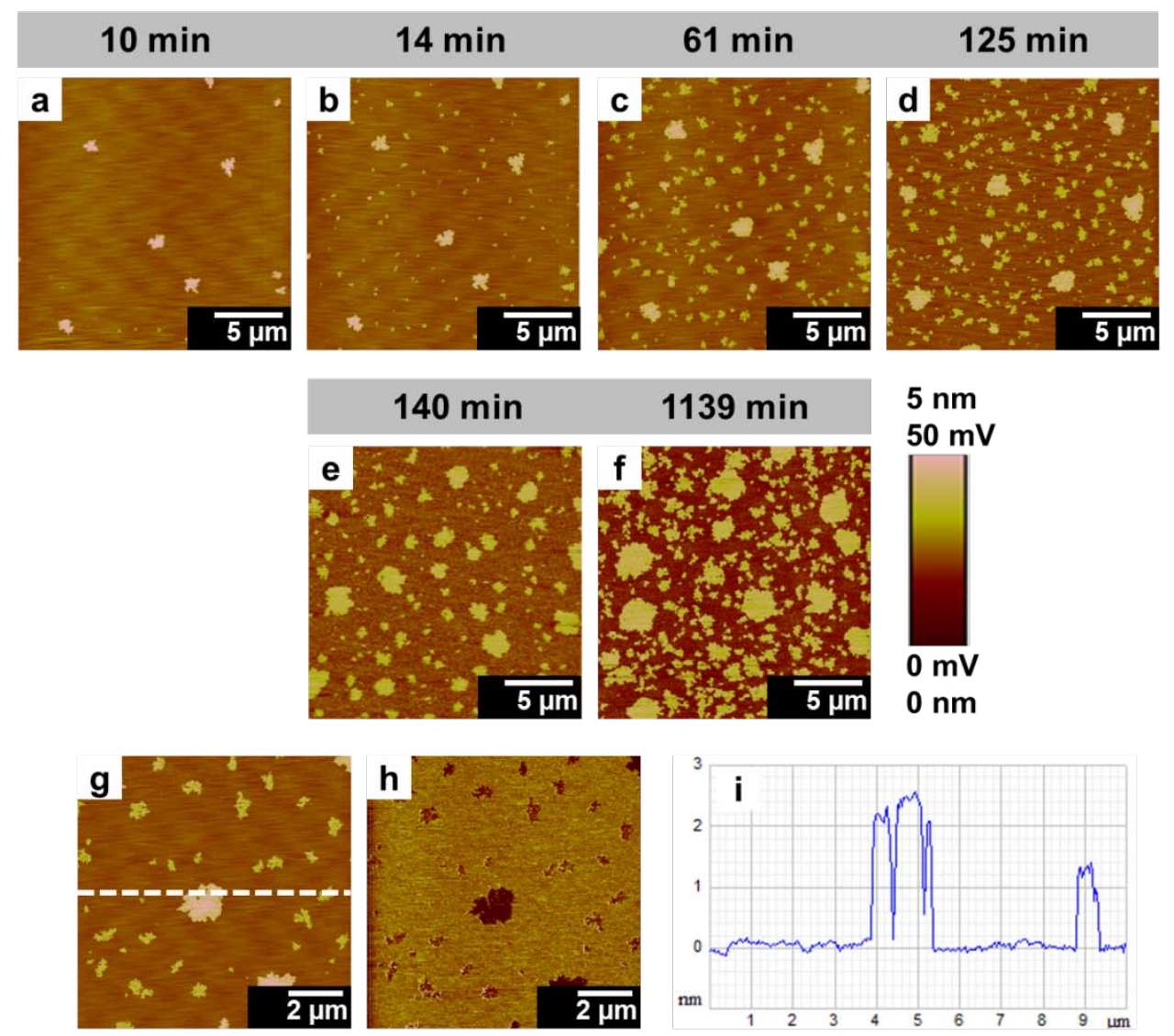

Fig. 7 Contact mode (a-d) and tapping mode $(e, f)$ height images showing film growth on mica with time in $0.001 \mathrm{M}$ stearic acid solution in dodecane; contact mode height $(\mathrm{g})$ and lateral force (h) images after $33 \mathrm{~min}$ in solution; line profile of $\mathrm{g}$ (i)

After 140 min in solution, tapping mode AFM showed that both large and small islands have undergone subsequent growth and that all islands now have a uniform height, Fig. 7(e). By depth profile analysis the film height is $1.5 \mathrm{~nm}$ and surface coverage is 0.16 . The AFM cantilever was disengaged and the controller switched off, whilst the mica substrate with supernatant stearic acid solution and liquid cell were left in situ overnight so that measurements could be continued the following day. After a total immersion time of 19 hours the islands had grown laterally and the height of these islands had also augmented. Depth profile analysis revealed that the film height was $2.1 \mathrm{~nm}$ and the surface coverage was 0.32 .

For a $0.001 \mathrm{M}$ stearic acid solution in dodecane, adsorbing molecules first adopt an orientation approximately perpendicular to the mica surface as the height of the initiallyformed islands is $2.3 \mathrm{~nm}$, a value not much less than that of an all-trans stearic acid molecule, which is reported to be $2.5 \mathrm{~nm}$ [43]. In the next stage of the growth process, smaller islands form across the surface. Like the large islands they have irregular shapes, however, they are not as high. The $1.4 \mathrm{~nm}$ height of the smaller islands suggests that the 
molecules are tilted from the surface normal by $56^{\circ}$. Growth then proceeds by the flattening of the larger islands. It is likely that the molecules in the larger islands tilt because this allows the molecules to spread out slightly without severely diminishing the stabilising lateral van der Waals forces between the alkyl chains. It is proposed that the molecules spread out to try to close the gaps between the islands so that a continuous monolayer film is achieved. After 2.5 hours all islands have a similar height of $1.5 \mathrm{~nm}$. After 19 hours the film islands have a uniform height of $2.1 \mathrm{~nm}$. The increased surface coverage observed after an extended immersion time suggests that a greater number of molecules are adsorbed to increase the packing efficiency and drive the molecules to adopt a more perpendicular orientation. There must be an energetic playoff between achieving a complete monolayer film and molecular tilt angle. If the molecules tilt by a greater angle, a larger area of the substrate can be covered. In a more concentrated $0.01 \mathrm{M}$ solution it seems that the equilibrium state of the monolayer is such that the molecules adopt a larger tilt angle to achieve a continuous film. However, in $0.001 \mathrm{M}$ solution it appears that a continuous film cannot be achieved; hence molecules retract into discrete islands where van der Waals forces are maximised by molecules adopting an orientation close to the surface normal.
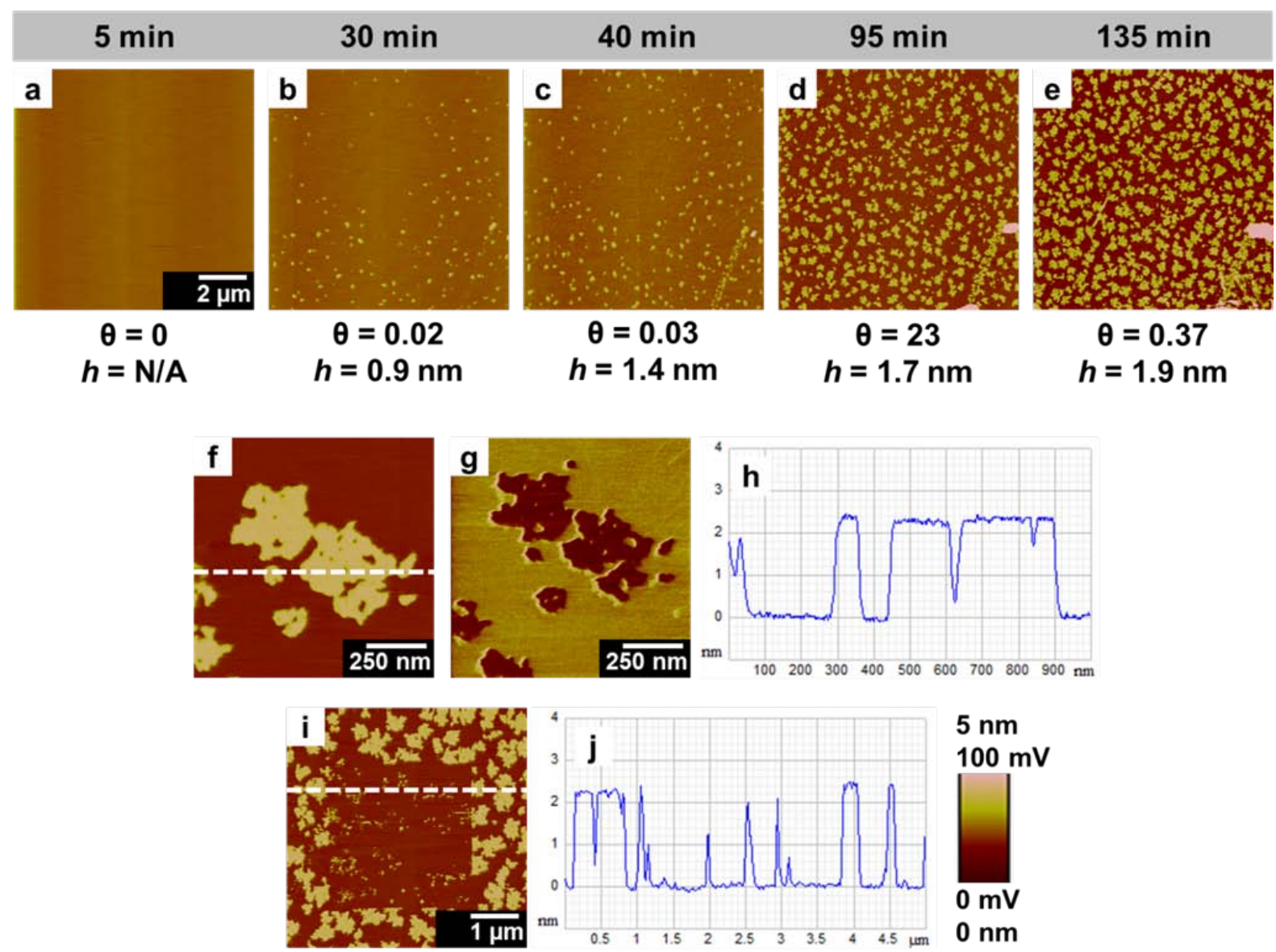

Fig. 8 Series of AFM height images showing film growth on mica with time in $0.01 \mathrm{M}$ elaidic acid solution in dodecane (a-e); contact mode height (f) and lateral force $(\mathrm{g})$ images with line profile (h); film destruction caused by loaded scanning (i and j); $\theta$ is surface coverage and $h$ is film thickness 
In $0.01 \mathrm{M}$ elaidic acid solution in dodecane it was observed that film growth occurred gradually over time, see Fig. 8. Elaidic acid molecules adsorbed forming irregularly-shaped islands similar to those observed in stearic acid solution. These islands increased in size and number throughout the experiment. The film height and surface coverage were observed to rise from $0.9 \mathrm{~nm}$ and 0.02 to $1.9 \mathrm{~nm}$ and 0.37 at immersion times of 30 and 135 min respectively. At smaller scan sizes, scanning near the tip pull-off point, the film height appeared to be higher, approximately $2.3 \mathrm{~nm}$, see Figs. 8(f,h) and 8(i,j). The elaidic acid islands displayed lower friction than the mica substrate, image as shown in Fig. 8(g), and were destroyed by loaded scanning at a scan size of $3 \mu \mathrm{m}$, Fig. 8(i).

In more dilute $0.001 \mathrm{M}$ elaidic acid solution in dodecane, no film formation was observed during an experiment that lasted $121 \mathrm{~min}$. Likewise, oleic acid was not observed to form a low friction film on mica in either 0.01 or $0.001 \mathrm{M}$ solution in dodecane. After an immersion time of 2 hours in 0.01 oleic acid solution a small number of features having heights of 0.5 to $30 \mathrm{~nm}$ and diameters of 50 to $350 \mathrm{~nm}$ were observed in tapping mode. These features were not sufficiently stable to be imaged by contact mode AFM and their lateral force is therefore not known.

\subsection{Stearic acid films at elevated temperature}

Experiments were carried out to determine the effect of temperature on the films formed on mica by stearic acid. This was achieved by using a sample heater located directly underneath the mica substrate. The mica surface was imaged in $0.0001 \mathrm{M}$ stearic acid solution in hexadecane; a low concentration was selected to ensure only partial monolayer coverage. After an immersion time of 1 hour the sample was heated from $22^{\circ} \mathrm{C}$ (room temperature) to $35^{\circ} \mathrm{C}$. At this temperature the $1.6 \mathrm{~nm}$ height film formed by stearic acid remained on the surface. When the sample was heated further to $45^{\circ} \mathrm{C}$ the film disappeared from the height image. Upon cooling the sample to $30^{\circ} \mathrm{C}$, the stearic acid film appeared to reform in the height image as islands. These islands had a height of $1.6 \mathrm{~nm}$, the same as the film height observed prior to heating.

The AFM tip was then disengaged and the sample and liquid cell left in situ for a period of 20 hours before the surface was imaged again. Scanning at large scan sizes revealed that the stearic acid film now consisted of large dendritic crystals. These crystals measured 50 to 70 $\mu \mathrm{m}$ across and had a height of $1.6 \mathrm{~nm}$. The sample was reheated from $24^{\circ} \mathrm{C}$ (room temperature) to $30^{\circ} \mathrm{C}$ and then in $5^{\circ} \mathrm{C}$ intervals to $45^{\circ} \mathrm{C}$, before being cooled in stages, as shown in Fig 9. As the temperature was increased the surface coverage appeared to decrease. Inside the dendritic crystals, the film was depleted by the expansion of preexisting small holes and the formation of new holes. The film was also depleted at the edge of these crystals whilst small islands located in between the crystals disappeared altogether at a temperature of $35^{\circ} \mathrm{C}$. At a temperature of $40^{\circ} \mathrm{C}$ the majority of the film had disappeared leaving only a few very small isolated islands. By $45^{\circ} \mathrm{C}$ the film had completely disappeared leaving a featureless surface except for the ripples due to localised slight buckling of the mica layers caused during cleavage, visible at the top of all images. Upon cooling the 
stearic acid film was observed to reform. Initially the film formed individual islands, which started to join up, adopting the same dendritic crystal structures observed before heating. A characteristic fault in the cleavage plane enabled us to account for $x y$ drift that occurred during the experiment and scanning across the edge of a fault in the mica cleavage plane showed that the dendritic crystals reformed in exactly the same location on the mica surface.

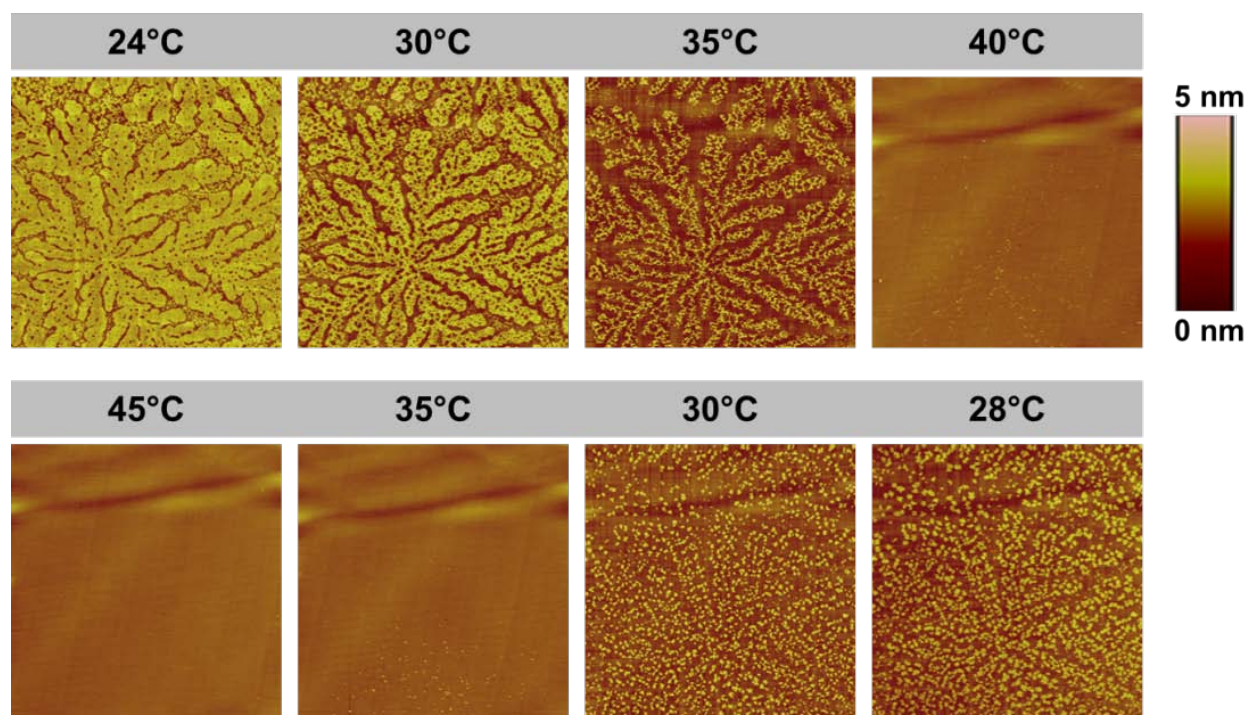

Fig. 9 The effect of temperature on stearic acid film during a second heating-cooling cycle; contact mode AFM height images of mica in $0.0001 \mathrm{M}$ stearic acid solution in hexadecane 20 hours after the first heating-cooling cycle, scan size $=50 \mu \mathrm{m}$

\subsection{Force spectroscopy of stearic acid film on mica}

Force-distance curves for a dodecane-cleaved mica surface in dodecane and after the injection of $0.001 \mathrm{M}$ stearic acid solution in dodecane are shown in Fig. 10. n.b. The actual concentration of stearic acid in the liquid cell was ca. $0.0004 \mathrm{M}$. In dodecane the surface appeared featureless, however, after the injection of stearic acid solution, low friction islands were observed. In stearic acid solution, force-distance curves were obtained for both the island and the inter-island regions. The pull-off force in $\mathrm{nN}$ was determined from these force curves by using the experimentally-obtained deflection sensitivity and cantilever force constant found by the reference cantilever calibration technique [38]. The distribution of pulloff forces for the different surfaces are also shown in Fig 10. The mean pull-off force for the mica substrate is $19 \mathrm{nN}$ in pure dodecane. In stearic acid solution, the low friction islands have a mean pull-off force of $0 \mathrm{nN}$ whilst the regions between these islands display a mean pull-off force of $6 \mathrm{nN}$. The lower adhesion force from the regions between the islands compared to that in pure dodecane could indicate one or both of the following: (i) stearic acid molecules are adsorbed onto the AFM tip and/or (ii) stearic acid molecules are adsorbed onto the mica surface between the islands. If adsorbed onto the mica surface, these molecules may be lying flat with their long axis parallel to the plane of the surface. Alternatively, they may form a very sparse covering of upright molecules which are elastically or plastically displaced by the tip when scanning in both contact and tapping 
mode. Either one of these reasons could provide an explanation as to why adsorbed stearic acid molecules are not visible outside of the islands in height images.
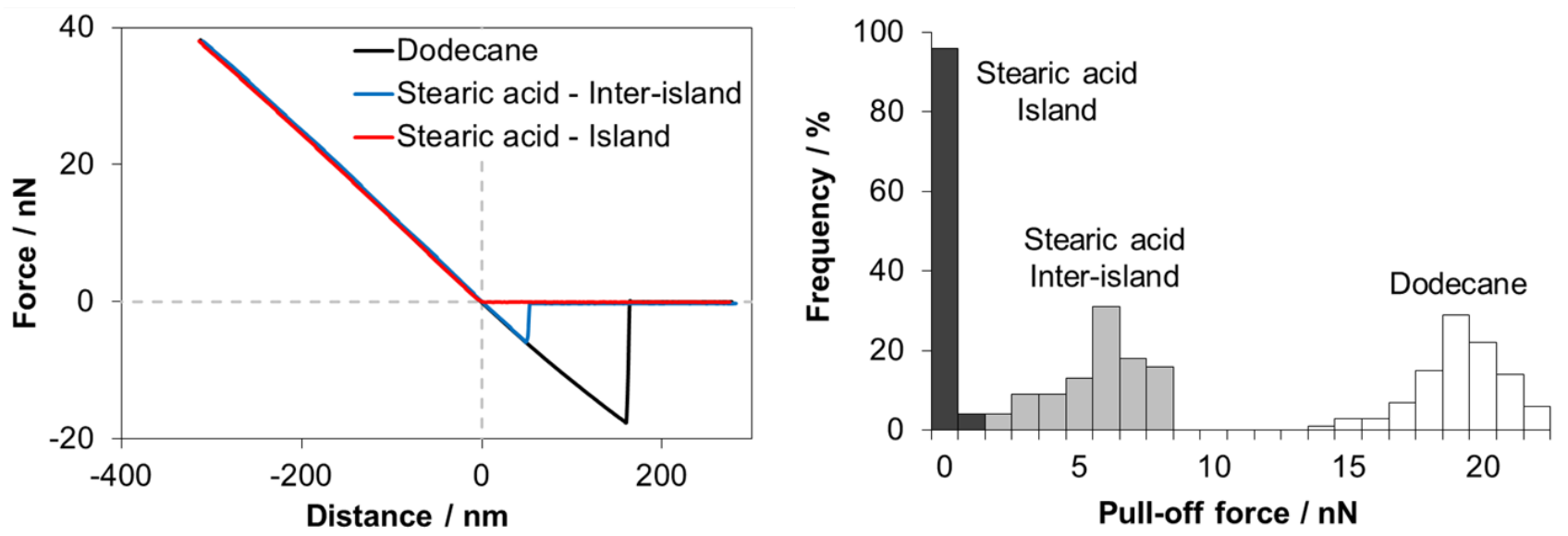

Fig. 10 Force-distance retraction curves (left) and distribution of pull-off forces (right) for mica in dodecane and stearic acid solution

\subsection{Stearic acid adsorption onto chemically modified mica}

The mica surface produced naturally by cleavage of the aluminosilicate layers has potassium cations located at its surface. However a mica surface with hydroxonium ions located on the surface in place if potassium, (H-mica), was created by ion exchange. This allowed an investigation of the role that metal cations play in SAM formation by stearic acid from solution in n-alkane.

The H-mica surface was first imaged in pure dodecane. Tapping mode AFM revealed a mostly flat surface but, at a small scan size of $1 \mu \mathrm{m}$ it is evident that the surface actually has rounded surface heterogeneities. The same area was then scanned in contact mode using a high deflection set point so that a relatively large load was applied by the tip. Upon decreasing the deflection set point and increasing the scan size to $3 \mu \mathrm{m}$ it was found that loaded scanning had created a recess in the surface, Fig. 11(a-c). It is likely that a thin water film remained on the hydrophilic mica surface after ion exchange in aqueous solution and it is postulated that this patterned surface was generated by the mechanical displacement of water molecules across the surface by the AFM tip. At the right and left hand edges of the area scanned under load the height is augmented which suggests that the displaced water molecules do not desorb but remain at the surface. This is the expected outcome given that water is insoluble in dodecane. The area from which water molecules have been removed exhibits lower friction than the water-covered $\mathrm{H}$-mica surface. This is also expected since the capillary forces between the tip and the surface would be greater when scanning the water film and this would lead to higher friction. The recess created in the thin water film is $1-2 \AA$ deep.

Studies of mica surfaces in humid environments have revealed that water can form a bilayer on mica, the first monolayer being phase I and the second monolayer being ice-like; with 
each monolayer having a height of $2 \AA$ [44-46]. In the phase I monolayer it is believed that water molecules bind to oxygen at the basal plane of the mica surface, whilst in the second monolayer the water molecules solvate $\mathrm{K}^{+}$ions at the surface, and interact with the underlying water molecules in the first monolayer and with neighbouring water molecules in the second monolayer [47]. In this case it is expected that solvation of $\mathrm{K}+$ ions would not occur since they have already been displaced during ion exchange in acid solution. It is not known whether the thin water film observed here is a monolayer, bilayer or even a thicker multilayer film. If the film is a bilayer, it is assumed that the first monolayer of water at the basal plane remains intact since the observed thickness of the film that is removed is indicative of a single monolayer of water.

Stearic acid solution, $0.001 \mathrm{M}$ in dodecane was then injected into the liquid cell and the same surface imaged further in tapping mode. The height and phase images appeared to be similar to those observed previously in dodecane. The tip was moved to a new area on the surface and scanning resumed, see Fig 11(d-I).
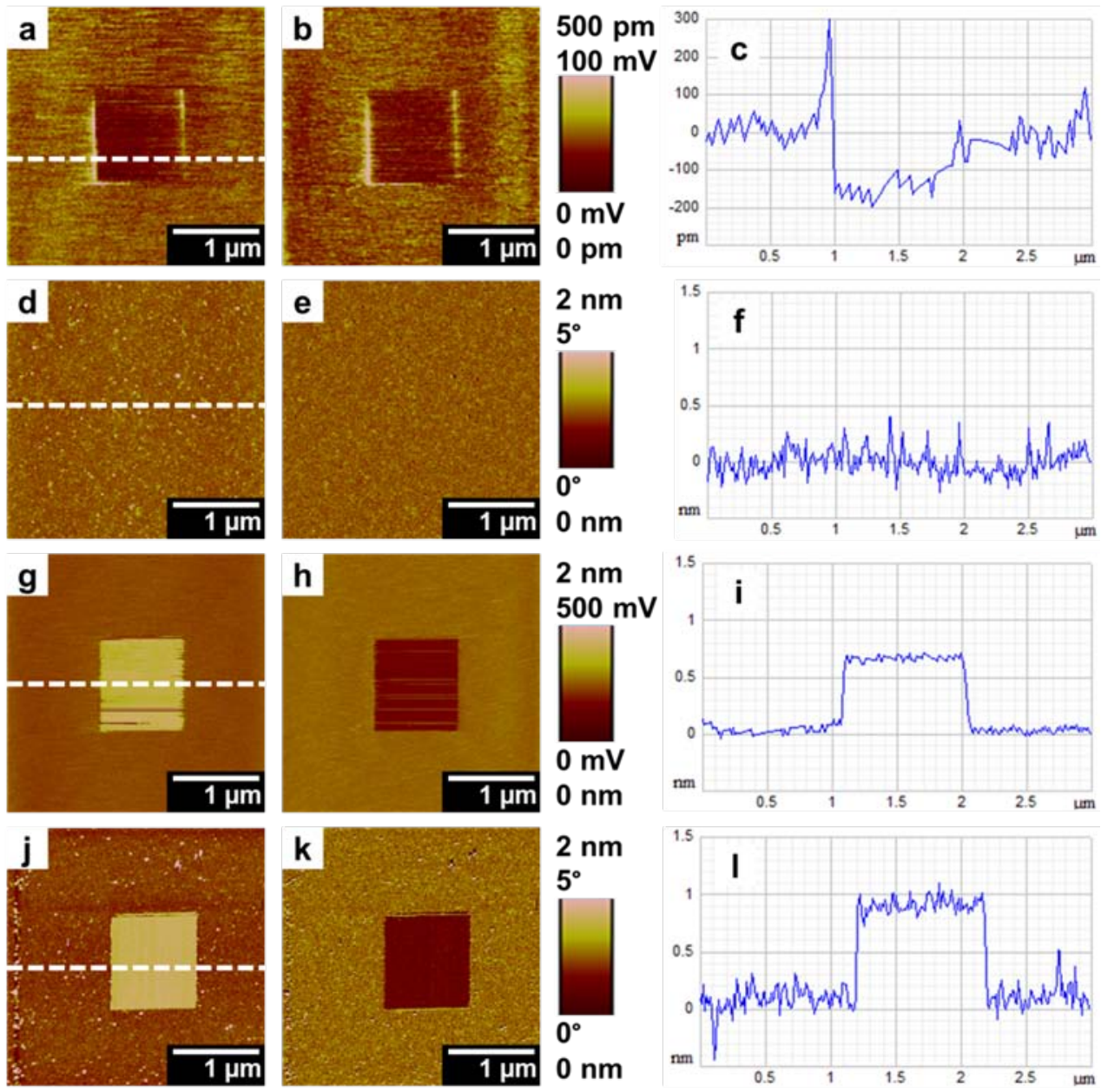

Fig. 11 AFM of H-mica in dodecane (a-c) and after injection of stearic acid solution (d-I); contact mode height (a) and lateral force (b) images after loaded scanning in dodecane; tapping mode height (d) and phase (e) images in stearic acid solution; contact mode height 
(g) and lateral force (h) and tapping mode height (j) and phase (k) images after loaded scanning in stearic acid solution; line profiles of $a(c), d(f), g(i)$ and $j(l)$

The surface appeared similar to that previously observed in dodecane by both tapping mode, Fig. 11(d-f) and contact mode. However, loaded scanning in contact mode at a scan size of $1 \mu \mathrm{m}$ resulted in the formation of a low friction film, Figs. 11(g) and 11(h). This film was also imaged in tapping mode and it was observed that the film exhibited a negative phase shift respective to the water covered H-mica surface, see Figs.11(j) and $11(\mathrm{k})$. By line profile analysis it was calculated that the height of the film was between 0.85 and $0.9 \mathrm{~nm}$ above the plane of the water covered H-mica surface as shown in Figs. 11(i) and 11(I) for contact and tapping modes respectively. Taking into account the height of the stearic acid film above the water covered $\mathrm{H}$-mica surface and the depth of the $\mathrm{H}$-mica surface below the thin water film implies that the thickness of the stearic acid film is between 1.0 and $1.1 \mathrm{~nm}$. This is indicative of a monolayer of stearic acid where the molecules are tilted by approximately $65^{\circ}$ from the surface normal. It is suggested that loaded scanning in stearic acid solution performed two, possibly related functions, firstly to remove a monolayer of surface-adsorbed water and secondly to promote the creation of a low friction organised monolayer of stearic acid. Removal of water alone was not sufficient to allow a film to form since this had already been achieved in the initial scan in dodecane, suggesting that the process of rubbing in stearic acid solution is a necessary stage in the formation of the film.

\subsection{Carboxylic acid films formed on quartz in friction tests}

Liquid cell AFM was used to study the friction surfaces of quartz discs lubricated by carboxylic acid solutions in hexadecane. The friction surfaces were prepared ex situ in a ball on disc (BOD) tribometer as decribed in the Experimental section of this paper. After the $\mathrm{BOD}$ friction test, the friction surface of the quartz disc remained wetted by lubricant during transference to the AFM. Additional lubricant from the friction test was then injected to completely fill the liquid cell.

The surface of a quartz disc after a BOD test with a steel ball in $0.01 \mathrm{M}$ stearic acid solution in hexadecane is shown in Fig. 12. It was observed that a low friction film had formed within the rubbed friction area. This film exhibited directionality, with regions of film growth running parallel to the direction of sliding employed in the BOD test. The direction of sliding, indicated by the arrow, runs diagonally across images 12(a) and 12(b). At a scan size of 1 $\mu \mathrm{m}$, it is apparent that the film consists of a network of irregularly shaped islands, similar to those observed on mica during in situ AFM experiments. Control of the cantilever deflection setpoint allowed for both height and friction information to be obtained. At a cantilever deflection of $0 \mathrm{~V}$, before the tip pull-off point, the stearic acid islands appear well-resolved in the height image. The islands have a height of $2 \mathrm{~nm}$, equivalent to a monolayer of stearic acid molecules possessing a $37^{\circ}$ molecular tilt from the surface normal. The simultaneously-obtained lateral force image gives little information since, under minimal load the lateral deflections of the cantilever were negligible. A larger load was achieved by increaing the cantilever deflection to $4 \mathrm{~V}$. Under increased load the lateral deflections of the 
cantilever were augmented and the low friction nature of the islands became apparent. However, the increased load led to a reduced island height of approximately $0.7 \mathrm{~nm}$. The decreased film thickness was likely to be due to load-induced tilting of the adsorbed stearic acid molecules.
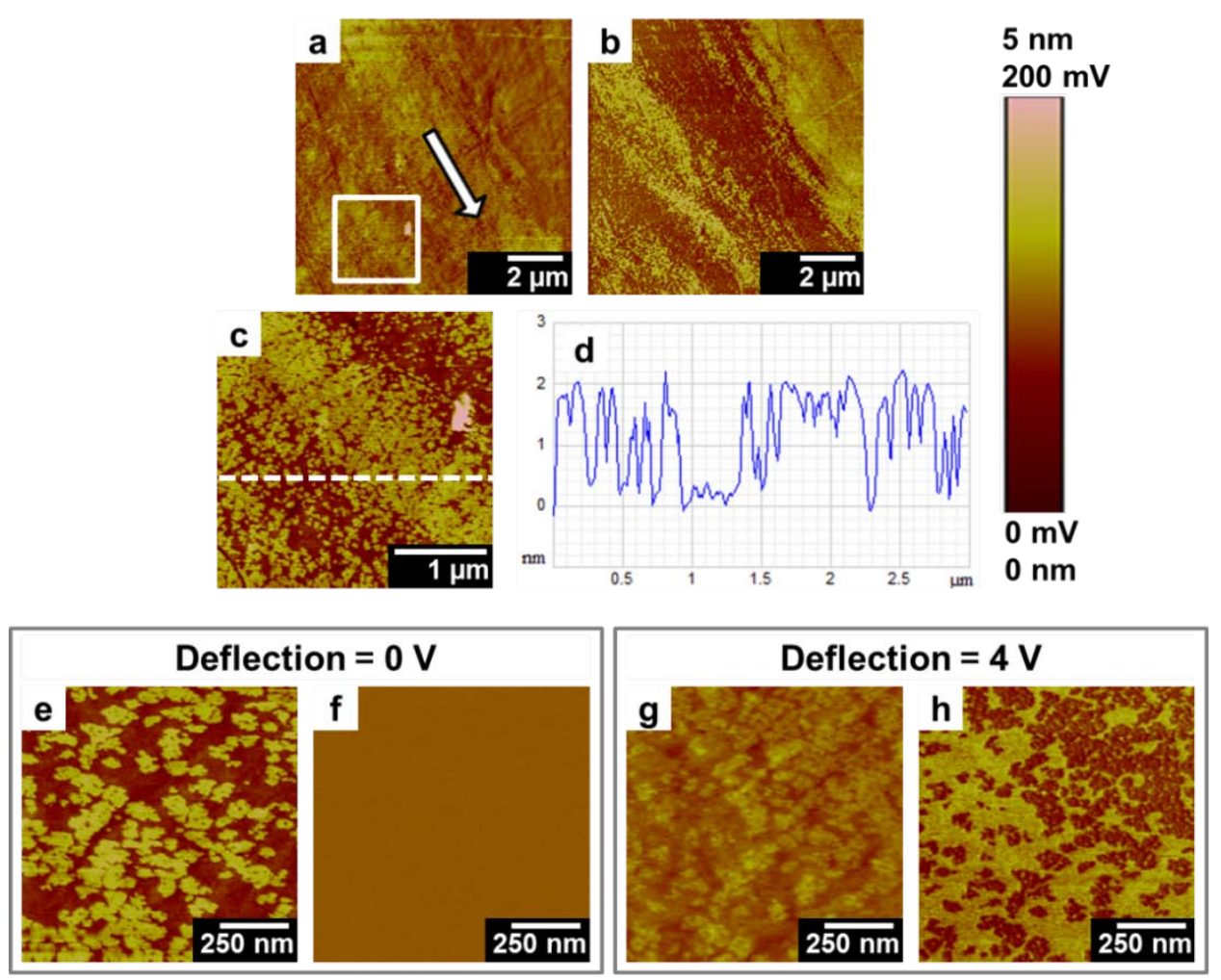

Fig. 12 Contact mode AFM height (a, c, e, g) and lateral force (b, $f, h)$ images showing film formed on quartz disc in a BOD friction test with a steel ball in $0.01 \mathrm{M}$ stearic acid solution in hexadecane; line profile of $c(d)$; arrow in image (a) indicates sliding direction

In a repeat experiment a similar result was achieved, however this time the film which formed inside the rubbed friction area consisted of a continuous monolayer rather than interconnected islands. This film had a height of $2 \mathrm{~nm}$ and displayed lower friction than the quartz surface. Loaded scanning at a cantilever deflection of $5 \mathrm{~V}$ resulted in removal of the low friction film, see Fig. 13.
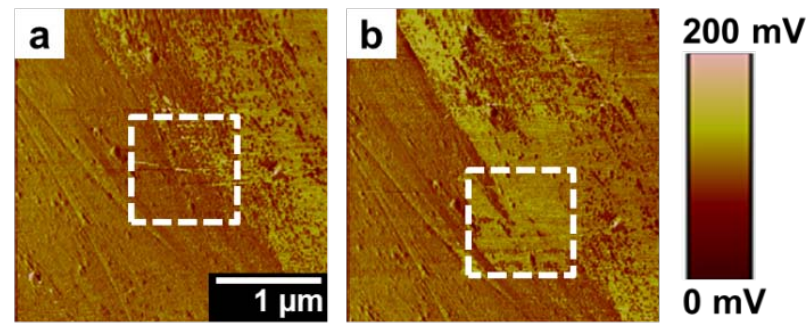

Fig. 13 Contact mode AFM lateral force images showing before (a) and after (b) film removal by loaded scanning; film formed on quartz disc in a BOD friction test with a steel ball in 0.001 $\mathrm{M}$ stearic acid solution in hexadecane 
It is postulated that the steel ball may have facilitated the formation of a low friction film during the BOD friction tests via a tribochemical reaction with entrained stearic acid molecules to yield insoluble iron stearate. To determine whether OFM tribofilm formation was dependent on the presence of iron in the contact, a repeat experiment was made using a quartz ball. The appearance of the quartz disc after a BOD test with a quartz ball in 0.01 $M$ stearic acid solution is shown in Fig. 14. It is observed that again a low friction film has formed on the rubbed friction surface. As before, the film exhibits directionality parallel to the direction of sliding used in the BOD friction test. Two different types of film are observed. That which formed at the centre of the contact consists of isolated islands of approximately 20 to $100 \mathrm{~nm}$ diameter, as seen in the profile shown in 14(e). These islands have a height of approximately $1.8 \mathrm{~nm}$, suggesting a monolayer tilted by $44^{\circ}$ from the surface normal. At the edge of the contact the film contains thicker regions where the height exceeds $4 \mathrm{~nm}$, as evident in the profile in 14(h). The stepwise increases in height strongly suggest that the monolayer film contains multilayer (bilayer and trilayer) regions, see line profile 14(h).
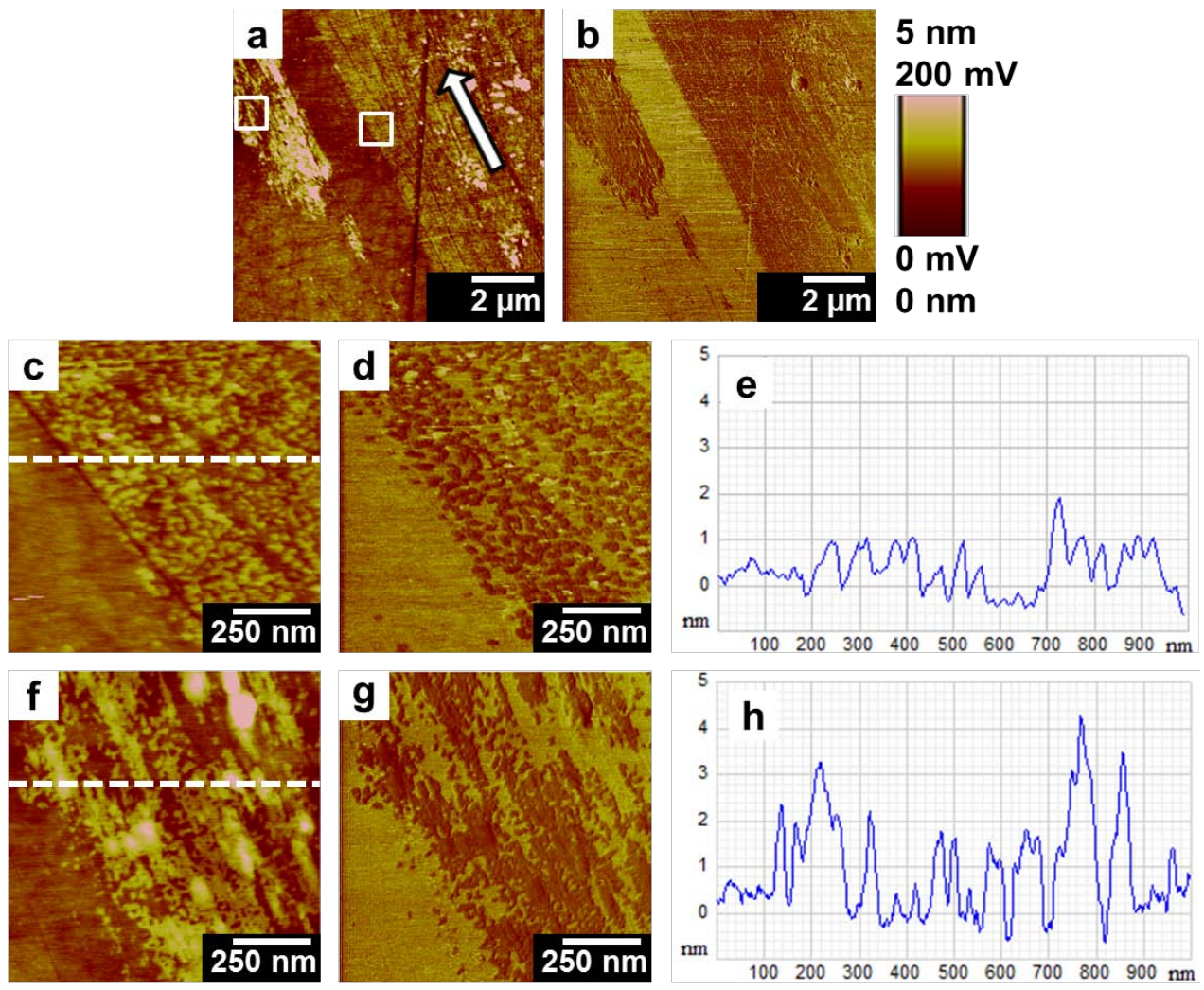

Fig. 14 Contact mode AFM height (a, c, f) and lateral force (b, d, g) images showing film formed on quartz disc in a BOD friction test with a quartz ball in $0.001 \mathrm{M}$ stearic acid solution in hexadecane; line profiles of $c(e)$ and $f(h)$

Film formation by mono-unsaturated oleic acid in a steel ball-quartz disc friction test was also investigated by AFM. A film formed on the rubbed friction surface of the quartz disc as shown in Fig. 15. Film growth was parallel to the direction of sliding employed in the BOD friction test but the film was quite different to the low friction monolayer films formed by stearic acid. Firstly, the film did not have a uniform height. Secondly, by LFM the film 
exhibited higher friction than the quartz surface, Fig. 15(h). The thickness of the film formed by oleic acid was not constant and large, local variations in height were detected. By line profile analysis it was calculated that the film thickness was approximately $7 \mathrm{~nm}$; however a value of $20 \mathrm{~nm}$ was reached at its thickest parts. At small scan sizes of $3 \mu \mathrm{m}$ and $1 \mu \mathrm{m}$, Figs. 15(d) and 15(e) respectively, it is observed that the film consists of many rounded globular features of approximately $100 \mathrm{~nm}$ diameter and 5 to $10 \mathrm{~nm}$ height. Thus, the film formed in oleic acid is not the typical monolayer or multilayer film expected of an OFM. It is postulated that the film consists of deposited aggregates, possibly of iron oleate. The reduced packing efficiency of the bent cis mono-unsaturated tails of oleyl molecules seems to make organised SAM formation unfavourable. Alternatively, the film may be the result of material transfer from the steel ball onto the quartz disc that occurred during the BOD friction test. As observed for stearic acid, loaded scanning at small scan sizes resulted in removal of the film, Fig. 15(g).
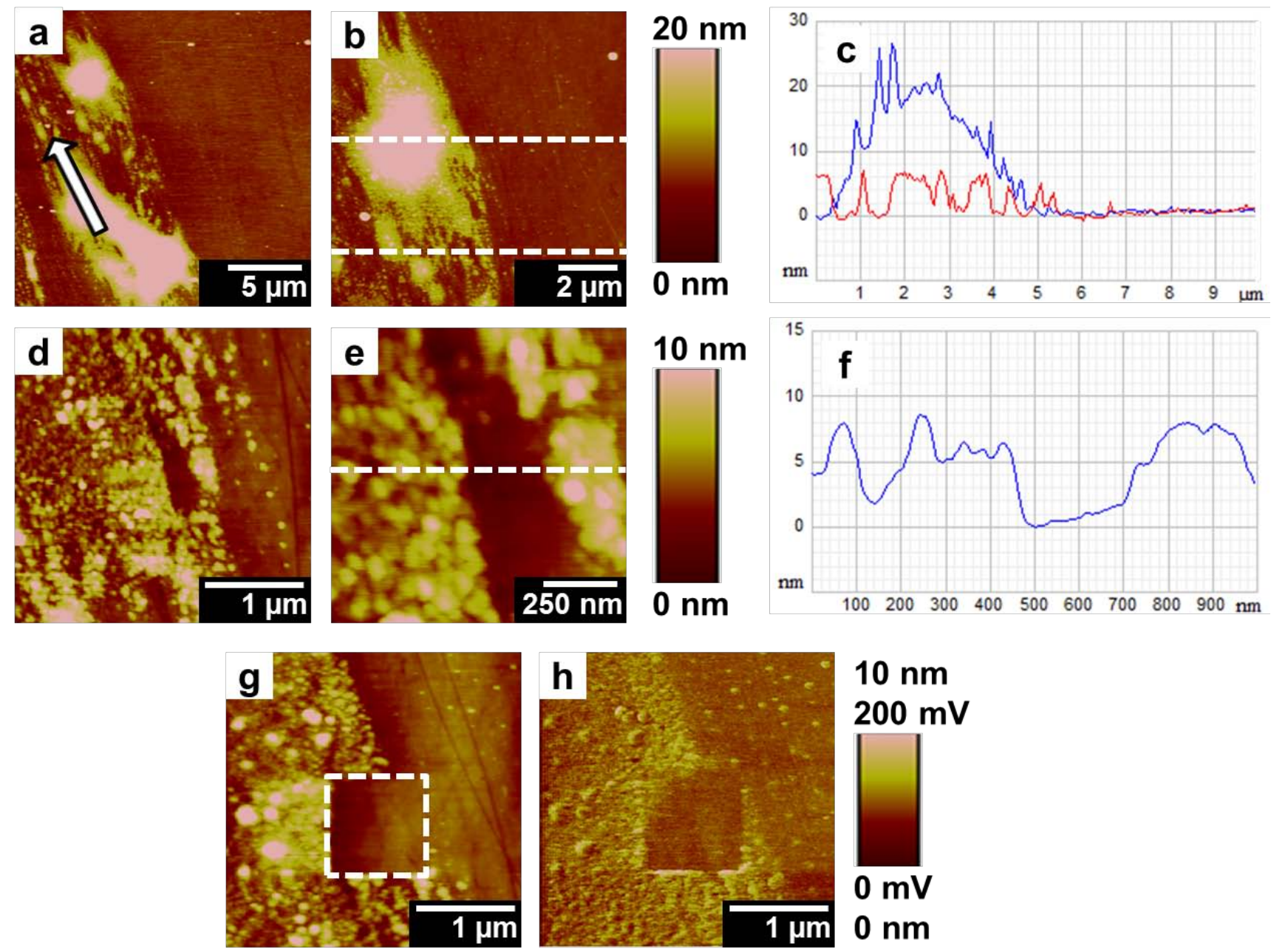

Fig. 15 Contact mode AFM height ( $a, b, d, e, g)$ and lateral force $(h)$ images showing film formed on quartz disc in a BOD friction test with a steel ball in $0.01 \mathrm{M}$ oleic acid solution in hexadecane; line profiles of $b$ (c) and e (f); arrow in image (a) indicates sliding direction; film removed by loaded scanning $(g, h)$ 
This study has shown the effectiveness of using liquid cell AFM to study boundary film formation by self-assembly of fatty acids on mica surfaces. Injection of fatty acid solution into a cell already containing the solvent, as shown in Fig. 2, means that the films formed by the amphiphile can be identified unambigiously. As shown in Figs. 7, 8 and 9, it is also possible to monitor the formation of the film as it develops over time of immersion and during changes of temperature.

The results show that stearic and elaidic acid both form irregular, approximately monolayerthickness island stuctures with a coverage that depends on concentration and solvent type. At $0.01 \mathrm{M}$ concentration, stearic acid in hexadecane forms essentially a monolayer of complete surface coverage quite rapidly, but at lower concentration there is only partial coverage. Even when full coverage is observed however, the surface film appears to have a structure, with some regions being slightly thicker and showing lower lateral force than others, as seen in Fig. 5.

When coverage is not complete the thickness of the film can be estimated. As shown in Fig. 7 this can vary with time of immersion. For stearic acid in dodecane, islands of height ca. $2.3 \mathrm{~nm}$ form initially, corresponding to almost vertically-oriented molecules. However as coverage increases, this thickness decreases, implying that the molecules become tilted to about $56^{\circ}$ from the normal. After even longer immersion time the film then starts to grow in thickness again. This suggests a thermodynamic trade-off between increased packing efficiency, leading to more vertical orientation, and substrate coverage that can be increased by tilting. It should be noted that the thickness and thus tilt angle of the monolayer will also depend on the pressure applied by the tip. In contact mode the applied pressure is dependent on the total cantilever deflection, the difference between the cantilever deflection during scanning and that when the tip is disengaged. Salmeron has discussed the subtle and often complicated response of adsorbed monolayers to applied load [48].

There was no evidence of any film thicker than one vertically-orientated monolayer being formed by either stearic or elaidic acid in n-alkane.

It is not possible using the AFM topography maps to establish whether the region between the monolayer islands is actually bare mica or has adsorbed amphiphile species. However AFM force-curves indicate that the pull-off force between the islands is much less than that from mica immersed in pure alkane. This strongly suggests that in the inter-island regions the mica surface has an adsorbed layer of the fatty acid, probably oriented horizontally. Such a layer would be only ca. $0.1 \mathrm{~nm}$ thick.

From Fig. 4 it is evident that both stearic and elaidic acid show considerably lower coverege in the alkane dodecane than in hexadecane. In general such differences should reflect variations in solvency and suggest that the acids are less soluble in hexadecane than in 
dodecane, and thus show more tendency to adsorb from solution. It is not immediately clear why this should be the case although Groszek has reported that stearic acid showed greater heat of adsoprtion on iron oxide from hexadecane than from heptane [49]. Both types of fatty acid should, of course, exist as dimers in alkane solution. Alternatively, the greater adsorption from hexadecane may reflect the elusive phenomenon known as "chain matching", where some authors have proposed that various amphiphilic surface adsorption processes and film properties are "stronger" when the amphiphile is dissolved in an alkane of identical chain length than when the chain length of the dissolved amphiphile and the alkane solvent are different [14,50-51]. One possible reason for this might be that a vertically-oriented monolayer film comprising a mixture of amphiphile and alkane might be strengthened by greater lateral side-chan interactions if the lengths of the alkyl groups were the same. Clearly a wider range of alkane solvents or fatty acid chain length should be studied to explore this more throroughly.

Contact mode AFM also shows that the film formed by fatty acids on mica surfaces is quite weak and rapidly displaced during repeated scanning. The mean Hertzian contact pressure during loaded scanning in contact mode was $1.6 \mathrm{GPa}$; this is based on a tip radius of $40 \mathrm{~nm}$ from SEM micrographs, a load of $38 \mathrm{nN}$ (cantilever deflection $5 \mathrm{~V}$ ), Young's moduli of 60 GPa and $280 \mathrm{GPa}$ for mica and silicon nitride respectively and Poisson ratios of 0.25 and 0.20 for mica and silicon nitride respectively [52-60]. Interestingly, the fatty acid film was not displaced laterally - there is no evidence of pile up at the edges of the scan, but instead appears to return to solution. This is in marked contrast to studies with long chain amines where contact mode AFM led to an increase in monlayer coverage during repeated scanning [1]. It is not clear why displacament of the film from the surface using AFM was not followed immediately by re-adsorption. The weakness of the film is also evident from the heated liquid cell work in Fig. 9 where a quite modest increase of temperature led to loss of the monolayer island structure. It is striking that the film recovers upon cooling in precisely the same island moropology as was present prior to heating. This suggests a memory effect, possibly due to slight imperfections in the mica substrate. Alternatively, there could be a reversible surface melting, where the alkyl tails of the stearic acid molecules become disorganised whilst the carboxyl head groups remain bound to the mica surface.

The three fatty acids, stearic acid, elaidic acid and oleic acid were compared. Stearic acid and elaidic acid solutions both formed monolayer-thickness, island-structured films, although stearic acid formed this much more rapidly, at lower concentration and to a higher coverage level than elaidic acid. The behaviour of oleic acid solution was very different. There was no evidence of monolayer island-structured film. Instead there was evidence in tapping mode of few, scattered round features of variable height $(0.5$ to $30 \mathrm{~nm})$ and diameter (50 to 350 $\mathrm{nm}$ ), which were too weak to image in contact mode. The composition of this not known though they may be small insoluble globules of potassium oleate.

The difference between the trans-alkenyl elaidic and cis-alkenyl oleic acid isomers has been noted by several authors in the contexts of adsorption [61], friction [14] and contact angle [62]. Elaidic acid, with an alkyl group arranged in a trans-geometry across the $\mathrm{C}=\mathrm{C}$ double 
bond is able to adopt an almost linear configuration and thus form a close-packed monolayer structure in a similar fashion, though not quite as effectively as, stearic acid. By contrast, the cis-double bond in oleic acid always has a bent arrangement which limits lateral side chain interactions. The difference is also reflected in the melting points of the two isomers. This confirms the need for amphiphiles to be able to close-pack in order to form monolayer-type boundary lubricating films.

The contribution of the $\mathrm{K}^{+}$ions on mica to fatty acid film formation was investigated by displacing these ions by hydroxium ions using ion exchange. When mica is cleaved, half of the $\mathrm{K}^{+}$ions at the interface are left on each surface and it was estimated that these would be sufficient to produce $40 \%$ vertically-oriented, condensed surface coverage of fatty acid potassium salt. It was thus conjectured that replacement of $\mathrm{K}^{+}$ions might prevent surface adsoprtion by fatty acid. In the event this simple concept was complicated because the exchange process left a film of water on the mica surfaces that could not be removed with a heated blow dryer. As shown in Fig. 11, this film was partially or fully displaced by contact mode AFM. Removal of this water film in stearic acid solution resulted in the imemdiate formation of a $1 \mathrm{~nm}$ thick, low friction film in the scanned region. This suggests that metal cations may not be essential for stearic acid to form a low friction film on mica, athough the apparent thickness of this film is lower than normally seen for the stearic acid/mica system.

In order to try to relate the above findings concerning boundary film formation by fatty acids, a few experiments were also carried out in which ex situ liquid cell AFM was applied to study immersed quartz disc surfaces taken from a stationary ball on roating disc friction tester. Quartz was used since it can be obtained with very low surface roughness. n.b. Mica proved an unsuitable substrate for BOD testing since it underwent catastrophic wear including fracture and delamination. Both steel and quartz balls were employed. With both steel and quartz balls, $0.01 \mathrm{M}$ stearic acid solution was found to markedly reduce friction and also to form the monolayer island structure films seen during in situ AFM studies on mica. As on mica, the film was removed by repeated scanning. With a quartz ball on quartz disc, parts of the film appear to be thicker than one monolyaer and to vary in a stepwise fashion suggesting bi- and tri-layers.

It is noteworthy that rubbing of the ball against the disc during the BOD friction test promoted the formation of a low friction film, while rubbing of the AFM tip against the disc destroyed this film. These two different outcomes can be explained by the different natures of the contacts. During the BOD experiment, the Hertzian contact area is $9300 \mu^{2}$ and the mean Hertzian contact pressure is $0.43 \mathrm{GPa}$. n.b. Values calculated for a steel (Young's modulus $=208 \mathrm{GPa}$ and Poisson ratio $=0.29$ ) on quartz (Young's modulus $=72 \mathrm{GPa}$ and Poisson ratio $=0.25$ ) contact. However during the AFM experiment the real area of contact is much smaller $\left(25 \mathrm{~nm}^{2}\right)$ and the mean contact pressure about 4 times higher. 
Liquid cell AFM has been used to study the in situ formation of boundary films of fatty acids from solutions in n-alkane onto mica. It has been found that stearic and elaidic acid generally form irregular islands of tens to hundreds of microns in diameter and thickness typically $1.6 \mathrm{~nm}$, corresponding to tilted monolayers. These are similar to the SAMs reported to be formed by several other amphiphilic systems on mica. For stearic acid, it is found that films form more rapidly and to a higher level of surface coverage from hexadecane than from dodecane. At relatively high concentrations of stearic acid in hexadecane, an almost complete monolayer is formed but lateral force measurements indicate that although complete, the film is not homogeneous but consists of domains of slightly different height and lateral force.

The use of in situ AFM enables temporal variations in the nature of boundary films immersed their solutions to be monitored, including studies of the kinetics of film build and the influence of temperature changes. These show that film formation proceeds by initial formation of small islands that expand and subsequently tilt to maximise coverage of the surface. Upon heating, stearic acid boundary films are lost but they reform at the same locations on the mica surface upon cooling.

The films formed by fatty acids on mica are progressively removed by contact mode scanning but can be studied without damage using tapping mode AFM.

The hypothesis that potassium ions present on freshly cleaved mica surfaces aid fatty acid adsorption by forming potassium salts was tested by replacing the $\mathrm{K}^{+}$by hydronium ions using acid washing. However, this resulted in a thin film of water on the mica surfaces that prevented straightforward interpretation. Part of this water layer could be removed by contact mode AFM scanning and when this was done in stearic acid solution, a thin boundary film was formed, suggesting that $\mathrm{K}^{+}$ions are not an essential component of the boundary film-forming process.

Ex-situ liquid cell AFM scans were also made of rubbed quartz surfaces from a sliding ballon-disc test and these showed that stearic acid formed similar monolayer island films on quartz in this macro-scale friction experiment as was found on mica.

Oleic acid solutions behaved quite differently from stearic and elaidic acids, forming irregular, globular films on both mica and on rubbed quartz surfaces. The cis-double bond geometry of oleic acid means that, unlike its trans-isomer elaidic acid or saturated stearic acid, it is unable to adopt a linear molecular configuration and so is less able to form closepacked monolayers. Instead, it may form small quantities of insoluble ferrous oleate.

From this study, it is clear that in situ liquid cell AFM is potentially a very powerful technique for studying the fundamental boundary film-forming properties of organic friction modifiers and other amphiphiles on smooth solid surfaces. 


\section{ACKNOWLEDGEMENTS}

The authors would like to thank Castrol Ltd, UK for supporting the study described in this article.

\section{REFERENCES}

1. Campen, S., Green, J.H., Lamb, G.D., Spikes, H.A.: In situ study of model organic friction modifiers using liquid cell AFM: self-assembly of octadecylamine. Submitted for publication in Tribol. Lett.

2. Wells, H.M., Southcombe, J.E.: The theory and practice of lubrication: the "Germ" process. J. Soc. Of Chem. Ind. 39, 51T-60T (1920)

3. Allen, H.S.: Molecular layers in lubrication. Discussion on Lubrication, Proc. Phys Soc. Lond. 32, p. 1s-34s (1919)

4. Hardy, H.B., Doubleday, I.: Boundary lubrication, - the paraffin series. Proc. Roy. Soc. Lond. A100, 550-557 (1922)

5. Bray, U.B., Moore, C.C., Merrill, D.R.: Improvements in diesel-engine lubricating oils. SAE Technical Paper No. 390125 (1939)

6. Sirianni, A.F., Puddington, I.E.: Friction reducing additives for lubricants. US Patent 2,689,224 (1954)

7. Bowden F.P., Tabor, D.: The Friction and Lubrication of Solids. Part I Chapter X. Publ. Clarendon Press, Oxford, 1971.

8. Beare, W.G., Bowden, F.P.: Physical properties of surfaces. I. Kinetic friction. Phil. Trans. Roy. Soc. Lond. A234, 329-354 (1935)

9. Bowden, F.P., Gregory, J.N., Tabor, D.: Lubrication of metal surfaces by fatty acids. Nature 156, 97-101, (1945)

10. Jahanmir, S.: Chain length effects in boundary lubrication. Wear 102, 331-349 (1985)

11. Studt, P.: Boundary lubrication: adsorption of oil additives on steel and ceramic surfaces and its influence on friction and wear. Tribol. Intern. 22, 111-119 (1989)

12. Langmuir, I.: Mechanical properties of monomolecular films. J. Franklin Inst. 218, 143171 (1934)

13. Bowden, F.P., Leben, L.: The friction of lubricated metals. Phil. Trans. Roy. Soc. Lond. A239, 1-27 (1940)

14. Jahanmir, S., Beltzer. M.: An adsorption model for friction in boundary lubrication. ASLE Trans. 29, 423-430 (1986) 
15. Salem, L.: Attractive forces between long saturated chains at short distances. J. of Chem. Phys. 37 2100-2113 (1962)

16. Beltzer, M., Jahanmir. S.: Role of dispersion interactions between hydrocarbon chains in boundary lubrication. ASLE Trans. 30, 47-54 (1987)

17. Spikes, H.A.: Boundary lubrication and boundary films. Proc. 19th Leeds-Lyon Symposium on Tribology, Leeds, Sept. 1992, Thin Films in Tribology, 331-346. Publ. Elsevier 1993.

18. Tao, Y.T.: Structural comparison of self-assembled monolayers of n-alkanoic acids on the surfaces of silver, copper, and aluminum. J Am. Chem. Soc. 115, 4350-4358 (1993)

19. Fox, N.J., Tyrer, B., Stachowiak, G.W.: Boundary lubrication performance of free fatty acids in sunflower oil. Tribol. Lett., 16 275-281 (2004)

20. Lundgren, S.M., Ruths, M., Danerlöv, K., Persson, K.: Effects of unsaturation on film structure and friction of fatty acids in a model base oil. J. Coll. \& Interf. Sci. 326, 5305364 (2008)

21. Lundgren, S.M., Persson, K., Mueller, G., Kronberg, B., Clarke, J., Chtaib, M., Claesson, P.M.: Unsaturated fatty acids in alkane solution: adsorption to steel surfaces. Langmuir 23, 10598-10602 (2007)

22. Campen, S., Green, J.H., Lamb, G.D., Atkinson, D., Spikes, H.A.: On the increase in boundary friction with sliding speed. Tribol. Lett. 48, 237-248 (2012)

23. Benitez, J.J., Heredia-Guerrero, J.A., Heredia, A.: Self-assembly of carboxylic acids and hydroxyl derivatives on mica. A qualitative AFM study. J. Phys. Chem. C111, 9465-9470 (2007)

24. Benitez, J.J., Heredia-Guerrero, J.A., Serrano, F.M., Heredia, A.: The role of hydroxyl groups in the self-assembly of long chain alkylhydroxyl carboxylic acids on mica. J. Phys. Chem. C112, 16968-16972 (2008)

25. Zhang, L.-J., Zhang, Y., Zhang, R.-J., Feng, X.-S.: "n situ AFM investigations on degradation of self-assembled monolayers on mica: Effect of humidity. Coll. and Surf. A: Physiochem. Eng. Aspects 293, 195-200 (2007)

26. Song, Y., Yao, Y., Chen, C., Cui, K., Wang, L.: Structural investigation of nhexadecanoic acid multilayers on mica surface: Atomic force microscopy study. Appl. Surf. Sci. 254, 3306-3312 (2008)

27. Taylor, C.E., Schwartz, D.K.: Octadecanoic acid self-assembled monolayer growth at sapphire surfaces. Langmuir, 19, 2665-2672 (2003)

28. Ostendorf, F., Schmitz, C., Hirth, S., Kuhnle, A., Kolodzief, J.J., Reichling, M.: How flat is an air-cleaved mica surface? Nanotechnol.19, 305705 (2008)

29. Leng, Y.: Hydration force and dynamic squeeze-out of hydration water under subnanometer confinement. J. Phys. Condens. Matter 20, 354017 (2008) 
30. Jahanmir, S.: Chain length effects in boundary lubrication. Wear 102, 331-349 (1985)

31. Murase, A., Ohmori, T.: ToF-SIMS analysis of model compounds of friction modifier adsorbed onto friction surfaces of ferrous materials. Surf. Interface Anal. 31, 191-199 (2001)

32. Dauchot, G., De Castro, E., Repoux, M., Combarieu, R., Montmitonnet, P., Delamare, F.: Application of ToF-SIMS surface analysis to tribochemistry in metal forming processes. Wear 260, 396-304 (2006)

33. Sahoo, R. R., Biswas, S. K.: Frictional response of fatty acids on steel. J. Coll. \& Interf. Sci. 333, 707-718 (2009)

34. Pashley, R.M.: Hydration forces between mica surfaces in aqueous electrolyte solutions. J. Coll. Interf. Sci. 80, 153-162 (1981)

35. Xu, L., Salmeron, M.: Effects of surface ions on the friction and adhesion properties of mica. Langmuir 14, 2187-2190 (1998).

36. Osman, M.A., Caseri, W.R., Suter, U.W.: $\mathrm{H}^{+} / \mathrm{Li}^{+}$and $\mathrm{H}^{+} / \mathrm{K}^{+}$exchange on delaminated muscovite mica. J. Coll. \& Interf. Sci. 198, 157-163 (1998).

37. Gaines, G.L., Rutkowski, C.P.: The extraction of aluminum and silicon from muscovite mica by aqueous solutions. J. Phys. Chem. 61, 1439-1441 (1957)

38. Ohler, B.: Practical advice on the determination of cantilever spring constants. Application note AN94, Veeco Instruments Inc., 2007.

39. Benitez, J.J., Salmeron, M.: The influence of chain length and ripening time on the self-assembly of alkylamines on mica. J. Chem. Phys. 125, 044708 (2006).

40. Li, B., Fujii, M., Fukada, K., Kato, T., Seimiya, T.: In situ AFM observation of heterogeneous growth of adsorbed film on cleaved mica surface. Thin Solid Films, 312, 20-23 (1998)

41. Xu, S., Cruchon-Dupeyrat, S.J.N., Garno, J.C., Liu, G.-Y., Jennings, G.K. ,Yong, T.-H., Laibinis, P.E.: In situ studies of thiol self-assembly on gold from solution using atomic force microscopy. J. Chem. Phys. 108, 5002-5012 (1998)

42. Leitner, T., Friedbacher, G., Vallant, T., Brunner, H., Mayer, U., Hoffmann, H.: Investigations of the growth of self-assembled octadecylsiloxane monolayers with atomic force microscopy. Mikrochim. Acta 133, 331-336 (2000)

43. Ulman, A.: An Introduction to Ultrathin Organic Films: From Langmuir-Blodgett to Self Assembly chapter 2.1, 111-113, Academic Press, New York, 1991.

44. Hu, J.; Xiao, X.-d.; Ogletree, D. F.; Salmeron, M.: The structure of molecularly thin films of water on mica in humid environments. Surf. Sci. 344, 221-236 (1995)

45. Miranda, P. B., Xu, L., Shen, Y. R., Salmeron, M.: Icelike water monolayer adsorbed on mica at room temperature. Phys. Rev. Lett. 81, 5876-5879 (1998). 
46. Xu, D., Liechti, K.M., Ravi-Chandar, K.: Mechanical probing of icelike water monolayers. Langmuir 25, 12870-12873 (2009)

47. Odelius, M., Bernasconi, M., Parrinello, M.: Two dimensional ice adsorbed on mica surface. Phys. Rev. Lett. 78, 2855-2858 (1997)

48. Salmeron, M., Generation of defects in model lubricant monolayers and their contribution to energy dissipation in friction. Tribol. Lett. 10, 69-79 (2001)

49. Groszek, A.J.: Heats of Preferential Adsorption of Boundary Additives at Iron Oxide/Liquid Hydrocarbon Interfaces. ASLE Trans., 13, 278-287 (1970).

50. Askwith, T.C., Cameron, A., Crouch, R.F.: Chain length of additives in relation to lubricants in thin film and boundary lubrication. Proc. Roy.Soc. Lond.. A 291, 500-519 (1966)

51. Hirano, F., Sakai, T., Kuwano, N., Ohno, N.: Chain matching between hydrocarbon and fatty acid as interfacial phenomena. Tribol. Intern. 20, 186-204 (1987)

52. McNeil, L. E.; Grimsditch, M.: Elastic moduli of muscovite mica. J. Phys.: Condens. Matter 5, 1681-1690 (1993)

53. Zhang, G.; Wei, Z.; Ferrell, R. E.: Elastic modulus and hardness of muscovite and rectorite determined by nano-indentation. Appl. Clay Sci. 43, 271-281 (2009)

54. Bobko, C. P.; Ortega, J. A.; Ulm, F.-J.: Comment on "Elastic modulus and hardness of muscovite and rectorite determined by nano-indentation" by G. Zhang, Z. Wei and R. E. Ferrel. Appl. Clay Sci. 46, 425-428 (2009)

55. Aleksandrov, K. S.; Ryzhova, T. V.: Elastic properties of rock-forming mineral II. Layered silicates. Bull. Acad. Sci. USSR. Geophys. Ser. English translation 12, 11651168 (1961)

56. Vaughan, M. T.; Guggenheim, S.: Elasticity of muscovite and its relationship to crystal structure. J. Geophys. Research 91, 4657-4664 (1986)

57. Seo, Y.-S.; Ichikawa, Y.; Kawamura, K.: Stress-strain response of rock-forming minerals by molecular dynamics simulation. J. Soc. Materials Sci. Japan 48 (3) Appendix, 13-20 (1999)

58. Abousleima, Y.; Tran, M.; Hoang, S.; Ortega, J. O.; Ulm, F.-J.: Geomechanics field characterization of Woodford Shale and Barnett Shale with advanced logging tools and nano-indentation on drill cuttings. The Leading Edge 29, 730-736 (2010)

59. Oliver, W.; Pharr, G.: An improved technique for determining hardness and elastic modulus using load and displacement sensing indentation experiments. J. Materials Res. 7, 1564-1583 (1992)

60. Mavko, G.; Mukerji, T.; Dvorkin, J.: 'The rock physics handbook', Cambridge University Press, New York, 1998. 
61. Arnold, T., Clarke, S.M.: Thermodynamic investigation of the adsorption of amides on graphite from their liquids and binary mixtures. Langmuir 24, 3325-3335 (2008)

62. Badre, C., Dubot, P., Lincot, D., Pauporte, T., Turmine, M.: Effects of nanorod structure and conformation of fatty acid self-assembled layers on superhydrophobicity of zinc oxide surface. J. Coll. \&Interf. Sci, 316, 233-237 (2007) 